\title{
Influence of Nonlinear Fluid Viscous Dampers on Seismic Response of RC Elevated Storage Tanks
}

\author{
Manisha V. Waghmare ${ }^{a^{*}}$, Suhasini N. Madhekar ${ }^{b}$, Vasant A. Matsagar ${ }^{\mathrm{c}}$ \\ ${ }^{a}$ Research Scholar, Dept. of Civil Engineering, College of Engineering Pune (COEP), Shivajinagar, SPPU, Pune-411005, India. \\ ${ }^{b}$ Professor, Dept. of Civil Engineering, College of Engineering Pune (COEP), Shivajinagar, SPPU, Pune-411005, India. \\ ${ }^{c}$ Dogra-Chair Professor, Dept. of Civil Engineering, Indian Institute of Technology (IIT) Delhi, Hauz Khas, New Delhi -110016, India.
}

Received 02 August 2020; Accepted 26 November 2020

\begin{abstract}
The numerical investigation on the seismic response of RC elevated liquid storage tanks installed with viscous dampers is presented. A discrete two-mass model for the liquid and multi-degree of freedom system for staging, installed with the dampers are developed for Reinforced Concrete (RC) elevated liquid storage tanks. The elevated tank is assessed for seismic response reduction when provided with Linear Viscous Damper (LVD) and Nonlinear Viscous Damper (NLVD), installed in the staging. The RC elevated liquid storage tanks are analyzed for two levels of liquid containment in the tank, $100 \%$ and $25 \%$ of the tank capacity. Three Configurations of placements of dampers viz. dampers at alternate levels (Configuration I and Configuration II) and dampers at all the panels of the staging of the tank (Configuration III) are considered. To study the effect of peak ground acceleration, eight real earthquake time histories with accelerations varying from $0.1 \mathrm{~g}$ to $0.93 \mathrm{~g}$ are considered. The nonlinearity in the viscous damper is modified by taking force proportional to various velocity exponents. It is found that the nonlinear viscous dampers with lower damping constant result in a comparable reduction in the response of RC elevated liquid storage tank, to that of linear viscous dampers with higher damping constant. A lower damping constant signifies compact the size of the damper.
\end{abstract}

Keywords: RC Elevated Liquid Storage Tank; Linear Fluid Viscous Damper; Nonlinear Fluid Viscous Damper; State-space; Seismic Analysis.

\section{Introduction}

The seismic safety of liquid storage tanks is of prime importance, and their response should be controlled using various control strategies. Liquid storage tanks are considered as lifeline structures and should remain functional during and after the earthquakes. Their performance during strong earthquakes is of critical concern. Most of the failures of large tanks during earthquakes are suspected of having resulted from the dynamic buckling caused by overturning moments of seismically induced liquid inertia and liquid surface slosh waves. Due to its complex dynamics and variable liquid levels, behavior of the elevated liquid storage tank cannot be estimated by the similar approaches used in the case of the high-rise buildings.

Several research works reported in the literature, guidelines, and specifications in international codes are available for seismic analysis and design of the liquid storage tanks. Housner (1963) [1] studied the dynamic behavior of ground supported and elevated water tank. Further, Haroun and Housner (1982) [2]; and Haroun [3] carried out vibration studies on ground supported, deformable cylindrical water tanks; and derived parameters of the mechanical model.

* Corresponding author: waghmaremv12.civil@coep.ac.in

http://dx.doi.org/10.28991/cej-2020-SP(EMCE)-09

(C) 2020 by the authors. Licensee C.E.J, Tehran, Iran. This article is an open access article distributed under the terms and conditions of the Creative Commons Attribution (CC-BY) license (http://creativecommons.org/licenses/by/4.0/). 
Apart from these studies, many researchers have worked on modeling of sloshing in containers and liquid dynamics. Ibrahim et al. [4] carried out extensive review of recent advances in liquid sloshing dynamics; further, the two equivalent mechanical models for modeling sloshing, namely mass-spring dashpot and pendulum models were discussed [5].

Specifications in international codes such as ACI 350.3 [6], and EN 1998-4 [7] are available for seismic analysis and design of RC liquid storage tanks. Jain and Jaiswal [8] and; Tung and Kiremidjian [9] illustrated the analysis procedure for elevated RC tanks considering two-mass model for liquid and assuming single lumped mass for the staging of the tank. Malhotra [10] carried out studies on ground supported base isolated tanks focusing on base shear, overturning moment, and axial compressive stresses. It was found that convective action does not contribute significantly to the overturning moment. Shenton III and Hampton [11] carried out response spectrum analysis of base isolated steel elevated water tanks, and found that seismic isolation is effective in reducing the tower drift, base shear, overturning moment, and tank wall pressures with a slight increase in convective displacement. Shrimali and Jangid [12], carried out studies on base isolated elevated steel liquid storage tanks considering two positions of isolators; at the top and bottom of the supporting tower structure. Abali and Uckan [13], carried out a parametric study on ground supported base isolated liquid storage tanks using FPS bearings. It was found that FPS would be effective in controlling the response of the slender tank compared to the broad tank. Moslemi et al. [14] used the finite element technique to investigate the seismic response of liquid filled tanks. It was concluded that the current practice of using the lumped mass technique as per ACI 350.3 standard in conjunction with ASCE 7-05, predicts the results with reasonable accuracy. Further, studies are carried out on water tank with different types of isolators viz. lead rubber bearing, variable frequency pendulum isolator and multiple friction pendulum system, by Shrimali and Jangid [15]; Panchal and Jangid [16], and Zhang et al. [17], respectively. Chalhoub and Kelly [18], carried out experimental study on base isolated cylindrical water tank. It was concluded that the low frequency that characterizes the motion of base isolated structures could be close to the sloshing frequencies of the contained fluid and affect the water displacement response. The researchers used two-mass model approach or three-mass model approach for modeling of liquid. The significant difference between these models is the number of lumped masses into which the liquid column is divided. Earthquake response of slender and broad liquid storage steel tanks isolated with variable curvature friction pendulum systems (VCFPS) was investigated by Panchal and Jangid [19]. It was observed that under near-fault ground motions, use of the VCFPS was quite effective in controlling the seismic response of liquid storage tanks. A brief review of the literature, related to the response of base-isolated structures under near-fault earthquakes and representation of nearfault earthquake motion using equivalent pulses, was presented by Saha et al. [20]. It was found that, the response reduction increases with the increase in isolation damping; however, the sloshing displacement was found to be less sensitive to the change in the isolation damping. Studies have also been reported for the ground-supported liquid storage tanks with semi-active dampers [21, 22], and elevated water tank with friction dampers [23].

During the earthquake, forces are induced in the elevated liquid storage tanks, which may lead to their failure. Many times, the conventional seismic resistant design approach without sophisticated vibration control devices cannot provide sufficient protection against the earthquake-induced forces. In aseismic design, either the elevated tanks are increased in their strength or the large mass of liquid is isolated. However, an alternate option is to install dampers in the staging. Supplemental dampers are especially suitable for tall structures which are generally not base-isolated owing to their flexibility, i.e. longer time periods. In order to reduce the seismic response of the liquid storage tanks, base isolation technique is effectively used by several researchers. It was found that the base isolation technique is effective in reducing base shear, while sloshing displacement is marginally increased.

Dampers have been effectively used for retrofitting works [24-26]. Also, in structures with high fundamental time period of vibration dampers have been proved to be very effective [27]. However, viscous dampers have not been examined for their use as seismic response control device for the elevated liquid storage tanks. Also, it is noted that previous researchers have considered staging of the elevated water tank as single lumped mass, which could not replicate the true response of the tank to the dampers, as dampers are to be installed in the staging. Hence, appropriate modeling of the elevated liquid storage tanks incorporating dampers is required to facilitate examining their effectiveness.

The specific objectives of the present study are: (i) to evaluate the seismic response of the RC elevated liquid storage tanks modeled with two- mass model of liquid and multi-degree of freedom system for staging, (ii) to study the influence of the velocity exponent, $\alpha$ on the effectiveness of viscous dampers with increased nonlinearity, (iii) to compare the seismic response of the RC elevated liquid storage tank installed with linear viscous dampers (LVDs) and nonlinear viscous dampers (NLVDs) subjected to eight different real earthquake ground motions; and (iv) to investigate the effect of positions of fluid viscous dampers on the response of the RC elevated liquid storage tanks.

The paper is organized in seven sections. This introduction section is followed by Section 2, which explains in brief the research methodology adopted in the paper. Section 3 describes the modeling of elevated liquid storage tank, where the two-mass model for liquid and multi-degree freedom system for framed staging is explained. Section 4 describes 
the modeling of fluid viscous damper. The numerical modelling of the tank installed with fluid viscous damper along with the procedure for solution of governing equation of motion is illustrated in Section 5. Further, Section 6 presents the numerical study and results. Main conclusions of the study are presented in Section 7.

\section{Research Methodology}

The research methodology is divided into three steps. The first step is mathematical modeling of RC elevated liquid storage tank and Fluid viscous damper. The second step MATLAB code is written for numerical modelling and solution of governing equation of motion by state-space method. In the final step, the seismic response of the RC tank without and with fluid viscous dampers (linear and nonlinear) is obtained. All the steps are discussed in detail in the succeeding sections from Section 3 to Section 6. Figure 1 illustrates the methodology.

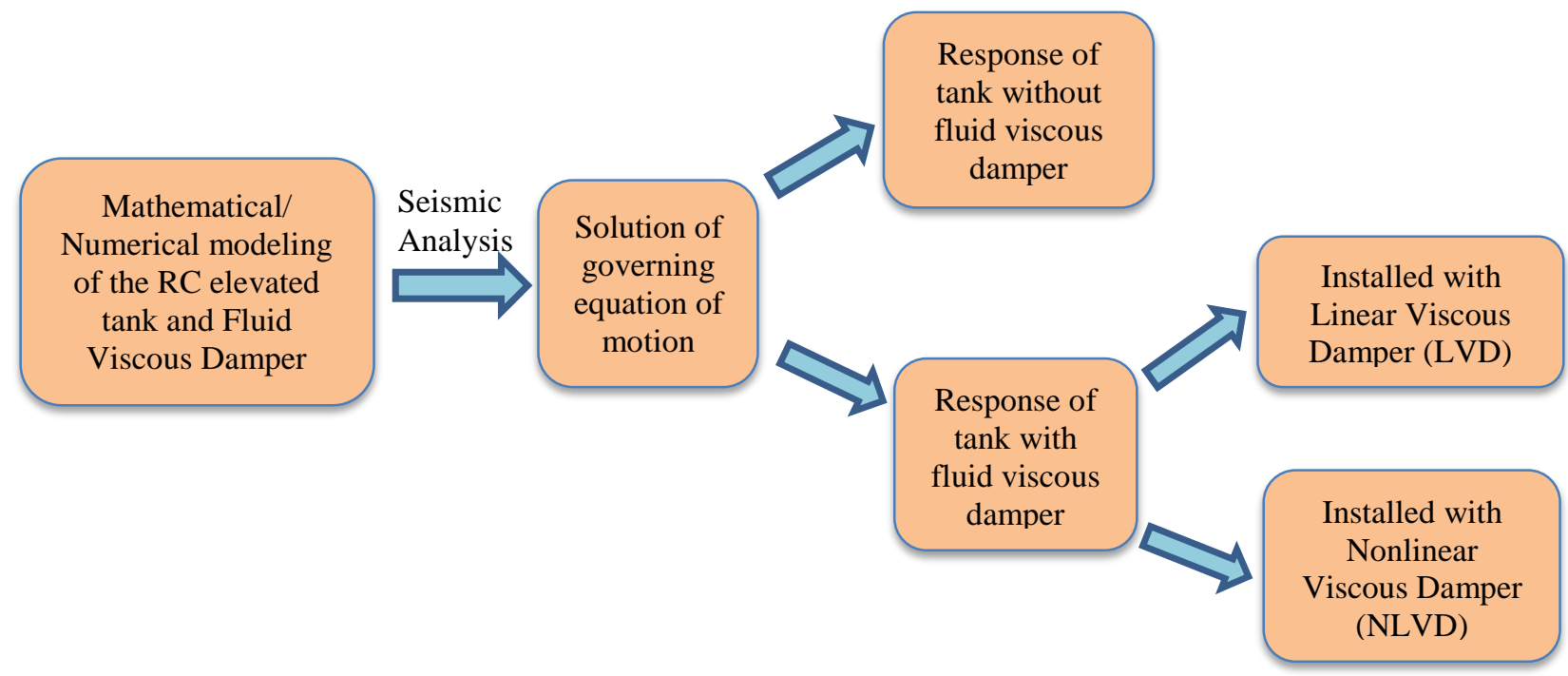

Figure 1. Research methodology

\section{Modeling of Elevated Liquid Storage Tank}

Previous study by (Jain, 2005) Jain and Jaiswal [8] showed that for analysis of the RC elevated liquid storage tanks, the container is considered rigid. Hence, the two-mass model can be conveniently used, which has also been recommended by the ACI 350.3 [6] and European standards, EN 1998-4 [7]. In the present study, a two-mass model with multi-degree freedom staging for the RC elevated liquid storage tank without and with dampers is presented. The response of tank, wherein fluid idealized as two-mass, is evaluated using the mechanical analog proposed by Housner [1], Haroun and Housner [2], and Housner [3]. In order to include the effect of the hydrodynamic pressure in the analysis, the tank is idealized by an equivalent spring mass model, which takes into account the effect of tank wallliquid interaction $[1,2,3,6,7]$. The following assumptions are made for the structural system under consideration [28]:

- The superstructure, i.e., structure of the tank above ground level, is considered to remain elastic during the earthquake excitation. This is a reasonable assumption, as the supplementary dampers attempt to reduce the earthquake response in such a way that the structure remains within elastic range.

- The tanks are with circular plan geometry, supported on staging, which consists of the inextensible columns providing vertical support and lateral stiffness.

- The system is subjected to a single horizontal component of the earthquake ground motion.

- The effects of soil-structure interaction (SSI) are not taken into consideration.

Figure 2 (a) shows the idealized schematic diagram of the RC elevated liquid storage tank considered in the study. Figure 2 (b) and Figure 2 (c) show the model of the tank with Configuration I and Configuration II for placement of the fluid viscous dampers installed in the staging. The case of installation of dampers at all the levels of staging is considered as Configuration III (Figure 2 (d)). Figure 2 (d) presents the mathematical model of the RC elevated liquid storage tank installed with the dampers (Configuration III). The parameters of the tanks considered are liquid column height $(H)$, radius $(R)$, and height of staging $\left(H_{s t}\right)$. The relative convective mass displacement, rigid mass displacement, and displacements at the horizontal bracing levels are denoted by $x_{c}, x_{r}$, and $x_{1}, \ldots, x_{p}$, respectively, where $p$ is number of panels in the staging; $\ddot{u}_{g}$ represents the earthquake ground acceleration. Further, $m_{1}, m_{2}, \ldots, m_{p}$ are the lumped masses at the bracing levels of the staging; $m_{t b}$ is the mass of tank base including floor beams; $m_{t w}$ is mass of tank wall 
including roof slab, and $m$ is the mass of liquid.

$m=\pi R^{2} H \rho_{l}$

In Equation 1, $\rho_{l}$ is the density of the contained liquid

\subsection{Two-mass Model}

Two-mass model was originally proposed by Housner [1] and later adopted by several researchers. The modified Housner's model presented in the ACI: 350.03 [6] is used in the present study. Figure 2 shows the schematic diagram of the tank model showing total height of the liquid inside the tank denoted by $H$ and radius for circular tank denoted by $R$. In this model, the convective mass $\left(m_{c}\right)$ of the liquid is considered to be connected to the solid tank wall with stiffness $\left(k_{c}\right)$ at height $H_{c}$ from the base of the container, whereas the rigid mass $\left(m_{r}\right)$ is connected rigidly to the tank wall with stiffness $\left(k_{i}\right)$ at a height $H_{r}$, while $H_{s t}$ denotes the height of the staging. The stiffness of the spring attached to the convective mass $\left(k_{c}\right)$ given by Equation 2, and the natural frequency of convective mass of liquid $\left(\omega_{c}\right)$ are given by Equation 3.

$$
\begin{aligned}
& k_{c}=\frac{1.84 m_{c} g}{R} \tanh (1.84 S) \\
& \omega_{c}=\sqrt{\frac{k_{c}}{m_{c}}}
\end{aligned}
$$

Where, $g$ is the gravitational acceleration and $S=H / R$ is the aspect ratio of the liquid column.

$$
c_{c}=2 \xi_{c} m_{c} \omega_{c}
$$

In Equation $4 C_{c}$ is the damping coefficient and $\xi_{c}$ is the damping ratio of the convective mass. If $t_{w}$ is the thickness of wall; the spring stiffness attached to the impulsive mass is given by, $k_{i}=m_{i}\left(\omega_{i}\right)^{2}$. The natural frequency of impulsive mass of liquid $\left(\omega_{i}\right)$ is obtained through Equations 5 to 7.

$$
\begin{aligned}
& \omega_{i}=C_{I} \frac{1}{H} \sqrt{\frac{1000 E}{\rho_{c}}} \\
& C_{l}=C_{w} \sqrt{\frac{t_{w}}{10 R}} \\
& C_{w}=0.09375+0.2039\left(\frac{H}{2 R}\right)-0.1034\left(\frac{H}{2 R}\right)^{2}-0.1253\left(\frac{H}{2 R}\right)^{3}+0.1267\left(\frac{H}{2 R}\right)^{4}-0.03186\left(\frac{H}{2 R}\right)^{5}
\end{aligned}
$$

The sloshing mass $\left(m_{c}\right)$ and mass rigidly connected to the container $\left(m_{r}\right)$ are expressed in terms of the total mass $(m)$ of the liquid as explained in Equations 8 and 9.

$$
\gamma_{c}=\frac{m_{c}}{m}=\frac{0.46}{S} \tanh (1.84 S)
$$

And:

$$
\gamma_{r}=\frac{m_{r}}{m}=\frac{S}{1.732} \tanh \left(\frac{1.732}{S}\right)
$$

Sloshing mass height $\left(H_{c}\right)$ and impulsive mass height $(\mathrm{Hr})$ are given by Equations 10 and 11, respectively.

$$
\begin{aligned}
\frac{H_{c}}{H} & =1-\frac{\cosh (1.84 S)-2.01}{(1.84 S) \sinh (1.84 S)} \\
\frac{H_{r}}{H} & =\frac{0.866}{S} \operatorname{coth}\left(\frac{1.732}{S}\right)-0.125
\end{aligned}
$$




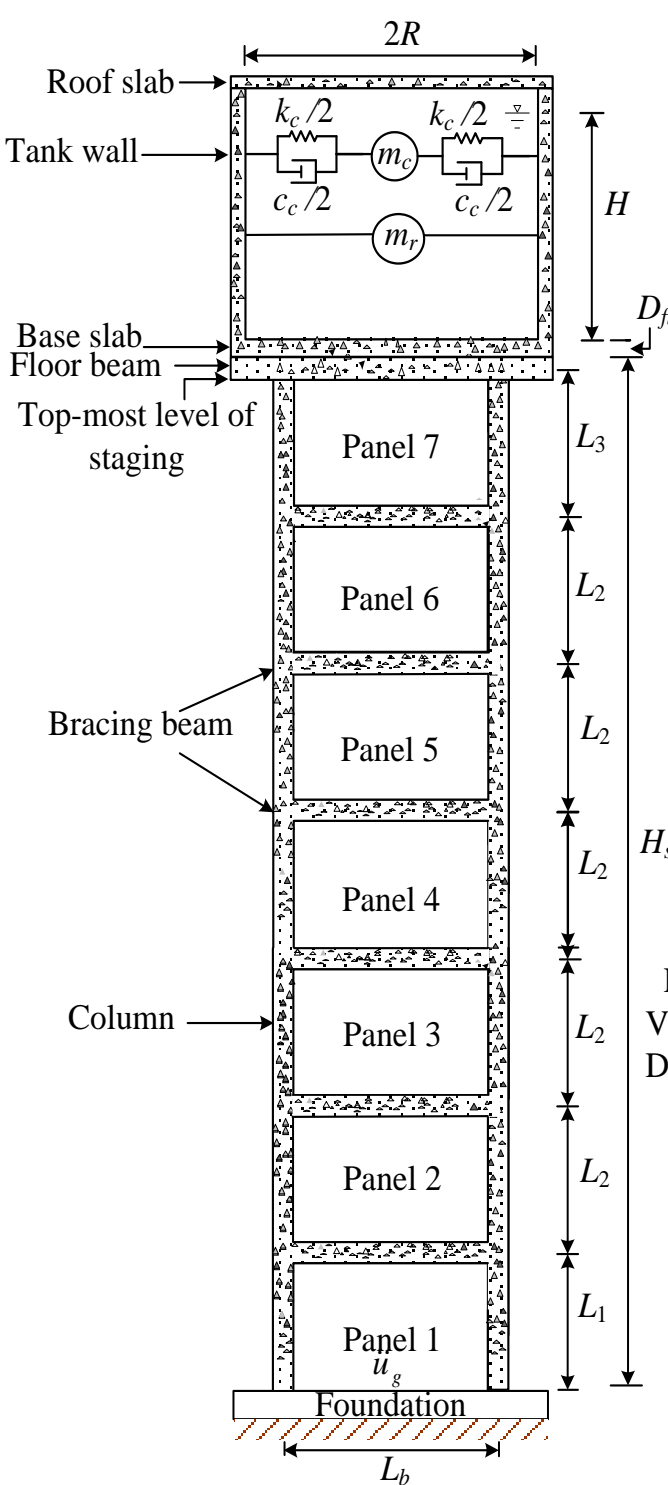

(a)

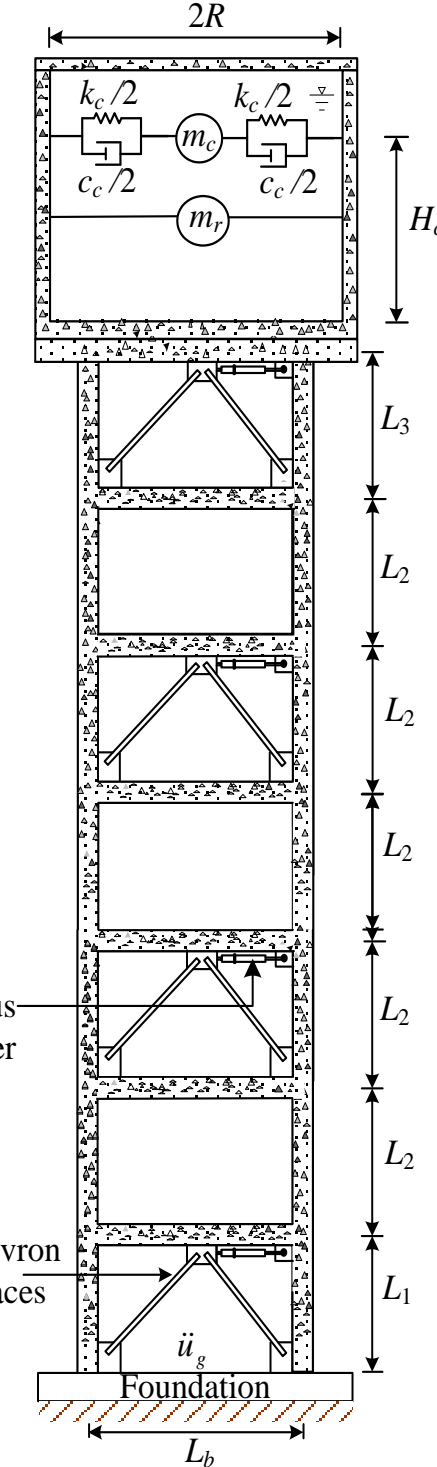

(b)

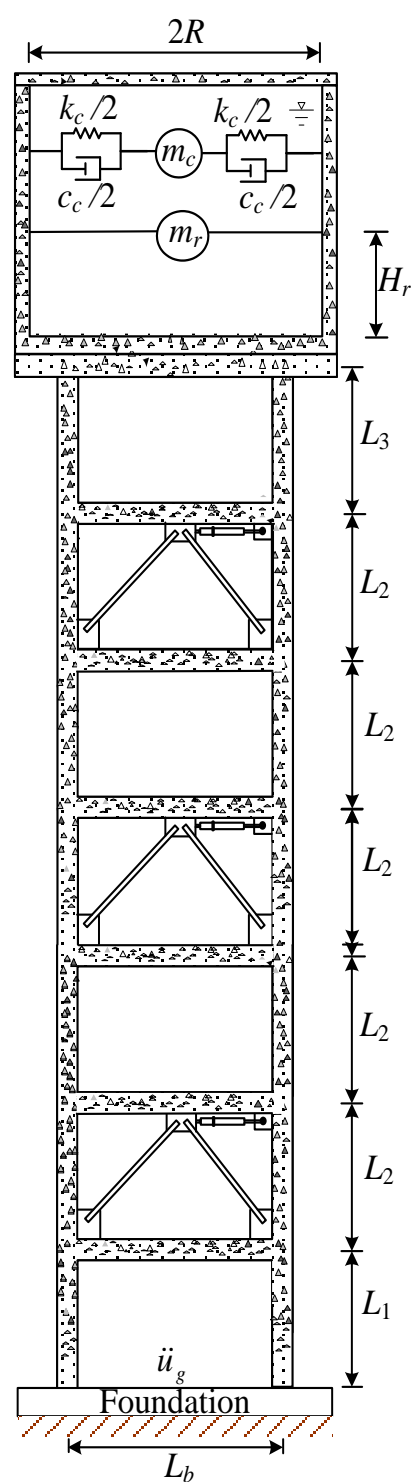

(c)

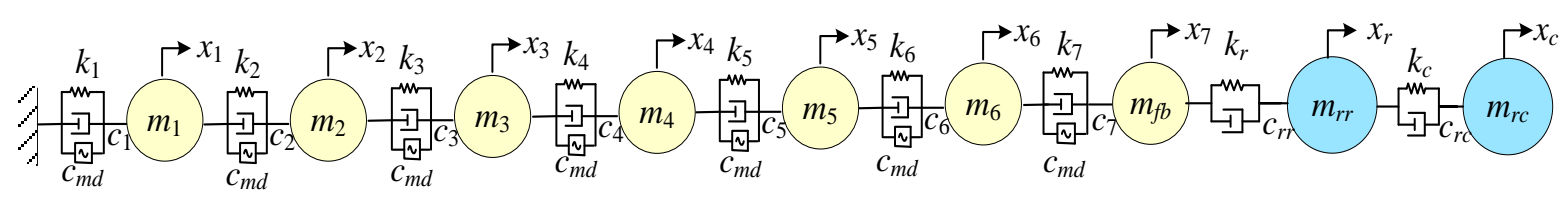

(d)
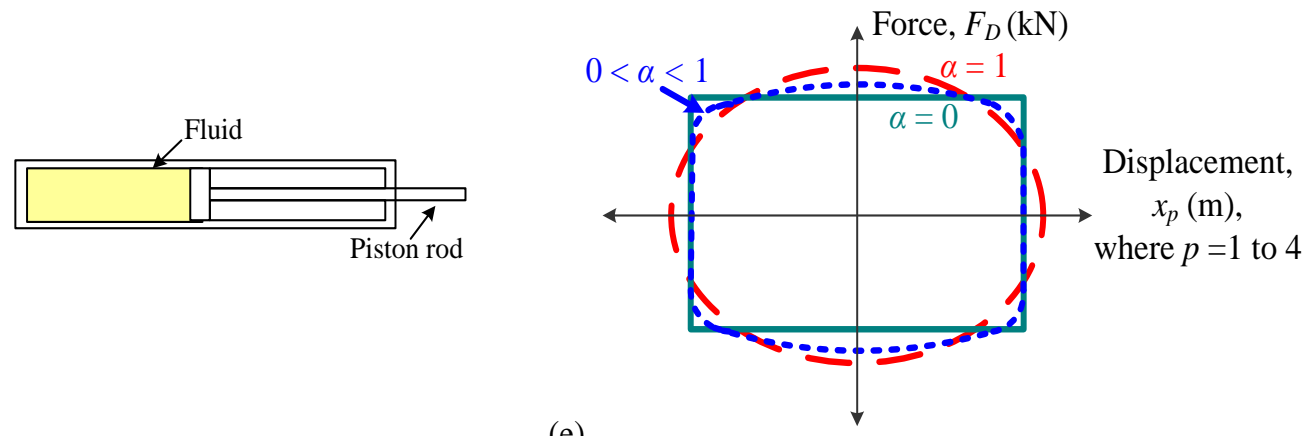

(e)

Figure 2. Schematic diagram of (a) the RC elevated liquid storage tank, (b) Configuration I for placement of dampers (c) Configuration II for placement of dampers (d) Mathematical model of the RC elevated liquid storage tank with fluid viscous dampers, and (e) Fluid viscous damper along with force-displacement loops for linear $(\alpha=1)$ and nonlinear $(0<\alpha<1)$ fluid viscous dampers. 
It should be noted that a separate degree-of freedom is attached to the floor/ bracing of the top-most panel and the rigid mass of the container and liquid. In the numerical modeling, coupling of masses is done in the following manner [28]:

- The mass of the tank base including the floor beams is denoted by $m_{t b}$ and; $m_{t w}$ is the mass of the tank wall including the roof slab.

- The masses, mc and $\mathrm{mr}$ are obtained from Equations 8 and 9, respectively.

- The masses thus obtained according to Housner's model [6] do not consider the mass of the container. However, the mass of the container is significant in case of the RC tanks. Hence in the present model, the total mass of the container, i.e., the mass of the tank wall including roof slab and the mass of liquid are considered together. The new sloshing mass $\left(m_{r c}\right)$ and rigid mass $\left(m_{r r}\right)$ are obtained; from the Equations 12 and 13, respectively.

$$
\begin{aligned}
& m_{r c}=\gamma_{c}\left(m+m_{t w}\right) \\
& m_{r r}=\gamma_{r}\left(m+m_{t w}\right)
\end{aligned}
$$

Further, $k_{1}, k_{2}, \ldots, k_{\mathrm{p}}$ are the stiffness values of the respective panels in the staging [29] obtained from Eq. (14).

$$
k_{p}=\frac{12 N_{c} E I_{c}}{L_{p}^{3}}\left(\frac{\left(E I_{b}\right) / L_{b}}{\left(E I_{b} / L_{b}\right)+\left(E I_{c} / L_{p}\right)}\right)
$$

Where, $E$ is the modulus of elasticity of concrete used for staging; $I_{b}$ and $I_{c}$ are the moment of inertia of the beams and columns, respectively; $L_{\mathrm{b}}$ is the span of the beam; $N_{c}$ is the number of columns in the staging; $L_{p}$ is the height of the panels in the staging. In the present study, the staging consists of 7 panels $(p=7)$. The damping associated with column members denoted by $c_{1}, c_{2}, \ldots, c_{p}$ is given by,

$$
c_{j}=2 \xi_{t} \sqrt{k_{j} m_{j}}
$$

In Equation 15, $j=1$ to $p$ and, $\xi_{t}$ is the damping ratio of the staging in the elevated tank. The mass, stiffness, and damping matrices are presented in Equations 16 to 18, respectively.

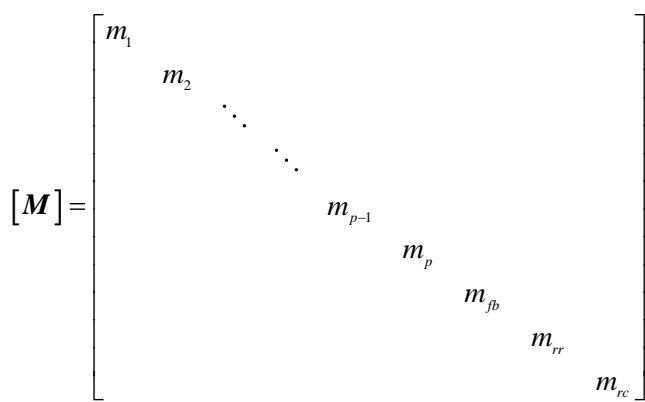

$$
\begin{aligned}
& {[\boldsymbol{K}]=\left[\begin{array}{cccccccccc}
k_{1}+k_{2} & -k_{2} & & & & & & & \\
-k_{2} & k_{2}+k_{3} & -k_{3} & & & & & & \\
& -k_{3} & k_{3}+k_{4} & -k_{4} & & & & & \\
& & \ldots & \ldots & \ldots & & & & \\
& & & \ldots & \ldots & \ldots & & & \\
& & & & -k_{p-1} & k_{p-1}+k_{p} & -k_{p} & & \\
& & & & & -k_{p} & k_{p}+k_{i} & -k_{i} & \\
& & & & & & -k_{i} & k_{i}+k_{c} & -k_{c} \\
& & & & & & & -k_{c} & k_{c}
\end{array}\right]} \\
& {[\boldsymbol{C}]=\left[\begin{array}{cccccccccc}
c_{1}+c_{2} & -c_{2} & & & & & & & \\
-c_{2} & c_{2}+c_{3} & -c_{3} & & & & & & \\
& -c_{3} & c_{3}+c_{4} & -c_{4} & & & & & \\
& & \cdots & \ldots & \ldots & & & & \\
& & & \ldots & \ldots & \ldots & & & \\
& & & & -c_{p-1} & c_{p-1}+c_{p} & -c_{p} & & \\
& & & & & -c_{p} & c_{p}+c_{r r} & -c_{r r} & \\
& & & & & & -c_{r r} & c_{r r}+c_{r c} & -c_{r c} \\
& & & & & & & -c_{r c} & c_{r c}
\end{array}\right]}
\end{aligned}
$$


$m_{f b}=m_{t b}+0.5 m_{t o p}$

In Equation 19, $m_{f b}$ is the top-most level mass of the staging; $m_{t o p}$ is the contribution of mass from the top-most panel of the staging, $c_{r r}$ is the damping associated with $k_{i}$ and $m_{r r}$; while $c_{r c}$ is the damping associated with $k_{c}$ and $m_{r c}$.

\section{Modeling of Fluid Viscous Damper}

Design of the Fluid Viscous Damper (FVD) is based on inertial flows, where non-flammable, non-toxic, environmentally safe, and thermally stable, silicone oil is forced through small orifices at high speeds (more than 200 $\mathrm{m} / \mathrm{s}$ ), generating high damping forces. This allows the damper to operate at relatively high operating pressures ${ }^{\text {[24] }}$. The output of this device is not affected by viscosity changes of the fluid. The control force $\left(F_{D}\right)$, offered by the fluid viscous damper as given by Goel [25] is,

$$
F_{D}=C_{m d}|\dot{u}|^{\alpha} \operatorname{sgn}(\dot{u})
$$

Where, $C_{m d}$ is the damping constant associated with every fluid viscous damper depending on its design; $\dot{u}$ is the relative velocity between two ends of the damper; $\alpha$ is the exponent varying between 0 and 1 ; and $\operatorname{sgn}(\cdot)$ is the signum function. The damper with $\alpha=1$ is called as linear viscous damper (LVD), in which damping force is directly proportional to the velocity; while, the damper with $\alpha \neq 1$ is called as nonlinear viscous damper (NLVD). A damper with $\alpha=0$ exhibits rectangular force-displacement loop resembling the friction damper. Figure 2 (e) shows schematic of fluid viscous damper and the force-displacement hysteresis loops for the LVD, NLVD-I, and NLVD-II in accordance with their energy dissipation characteristics.

\section{Numerical Modeling and Solution}

In this section, numerical modeling procedure and solution of governing differential equations for time history analysis of the RC elevated liquid storage tank, with staging modeled as multi-degree of freedom system, installed with the viscous damper is illustrated.

\subsection{Equation of Motion}

The governing differential equation of motion under earthquake excitation, with added supplemental viscous dampers, is given by Equation 21.

$$
[\boldsymbol{M}]\{\ddot{\boldsymbol{X}}(t)\}+[\boldsymbol{C}]\{\dot{\boldsymbol{X}}(t)\}+[\boldsymbol{K}]\{\boldsymbol{X}(t)\}=\left\{\boldsymbol{F}_{e}(t)\right\}+[\boldsymbol{L}]\left\{\boldsymbol{f}_{c}(t)\right\}
$$

Where, $[M]_{n \times n}$ is mass matrix; $[K]_{n \times n}$ is stiffness matrix; and $[C]_{n \times n}$ is damping matrix. The control force distribution matrix; $[L]_{n \times n}$ is given by Equation 22.

$$
[L]=\left[\begin{array}{ccccccccc}
1 & -1 & 0 & 0 & 0 & 0 & 0 & 0 & 0 \\
0 & 1 & -1 & 0 & 0 & 0 & 0 & 0 & 0 \\
0 & 0 & 1 & -1 & 0 & 0 & 0 & 0 & 0 \\
0 & 0 & 0 & 1 & -1 & 0 & 0 & 0 & 0 \\
0 & 0 & 0 & 0 & 1 & -1 & 0 & 0 & 0 \\
0 & 0 & 0 & 0 & 0 & 1 & -1 & 0 & 0 \\
0 & 0 & 0 & 0 & 0 & 0 & 1 & -1 & 0 \\
0 & 0 & 0 & 0 & 0 & 0 & 0 & 0 & 0 \\
0 & 0 & 0 & 0 & 0 & 0 & 0 & 0 & 0
\end{array}\right]
$$

Where, $\left\{F_{e}(t)\right\}=\left\{F_{1}(t), F_{2}(t) \ldots F_{n}(t)\right\}^{T}$ is a vector such that $\left\{F_{e}(t)\right\}=-[M]\{r\} \ddot{u}_{g}(t)$ where, $\{r\}=\{1,1, \ldots, 1\}^{T}$ is the influence coefficient vector. Here, the degrees of freedom are: $n=9$. Also, $\left\{f_{c}(t)\right\}=\left\{F_{D 1}(t), F_{D 2}(t), \ldots, F_{D n}(t)\right\}^{T}$ is a vector containing the control force exerted by the dampers corresponding to each degree of freedom, $n$. Moreover, $\{X(t)\}$ is the vector of displacement of the masses relative to the ground, expressed as:

$$
\{\boldsymbol{X}(t)\}=\left\{x_{1}(t) \quad x_{2}(t) \quad \cdots \quad x_{r}(t) \quad x_{c}(t)\right\}^{T}
$$

In Equation 23, $x_{1}=\left(d_{1}-u_{g}\right), x_{2}=\left(d_{2}-u_{g}\right), \ldots, x_{r}=\left(d_{r}-u_{g}\right), x_{c}=\left(d_{c}-u_{g}\right) ; u_{g}$ is the ground displacement; and $d_{c}, d_{r}$, and $d_{p} \ldots, d_{1}$ are the absolute displacements at the level of convective mass level, rigid mass level, and bracing level masses, respectively. 
The hydrodynamic forces are imparted on the tank wall, which transmits forces on the staging underneath. The seismic forces induced in the staging are controlled using the fluid viscous dampers. Therefore, the effectiveness of such supplementary damping system is assessed in terms of the reduction of displacements, base shear, and overturning moment generated in the staging of the elevated tank during earthquake. The base shear, $V_{b}$ (Equation 24) and the overturning moment, $M_{o}$ (Equation 25) in the staging at the foundation level are expressed as:

$$
\begin{aligned}
V_{b}= & m_{r c} a_{c}+m_{r r} a_{r}+\cdots+m_{3} a_{3}+m_{2} a_{2}+m_{1} a_{1} \\
M_{o}= & m_{r c} a_{c}\left(H_{c}+D_{f s}+H_{s t}+\frac{D_{f b}-D_{f s}}{2}\right)+m_{r r} a_{r}\left(H_{r}+D_{f s}+H_{s t}+\frac{D_{f b}-D_{f s}}{2}\right)+\cdots \\
& +m_{3} a_{3}\left(2 L_{2}+L_{1}\right)+m_{2} a_{2}\left(L_{2}+L_{1}\right)+m_{1} a_{1} L_{1}
\end{aligned}
$$

Where, the height of the staging, $H_{s t}=L_{1}+(p-2) L_{2}+L_{3}, D_{f s}$ is the depth of floor slab, and $\mathrm{D}_{f b}$ is the depth of floor beam. The absolute accelerations at the different level of masses are denoted by $a_{c}, a_{r}, a_{p}, \ldots, a_{2}, a_{1}$.

\subsection{State-space Solution}

In the state-space method, the response of the system is analyzed using both; displacement and velocity, as independent variables, called as states [30]. Vector, $z(t)$ is defined to represent both states viz. displacement and velocity of the system. These two independent response variables in the present study are expressed as Equation 26:

$$
z(t)=\left\{\begin{array}{c}
X(t) \\
\dot{X}(t)
\end{array}\right\}
$$

Every degree of freedom is associated with two states, viz. displacement and velocity. Thus, if the degree of freedom of a structure is $n$, then there will be $2 n$ states, first $n$ for the displacement and remaining $n$ for the velocity. It follows that Equation 21 can be written in the equivalent state-space form presented in Equation 27.

$$
\dot{\boldsymbol{z}}(t)=\left\{\begin{array}{c}
\dot{\boldsymbol{X}}(t) \\
\ddot{\boldsymbol{X}}(t)
\end{array}\right\}=\left[\begin{array}{cc}
\mathbf{0} & \boldsymbol{I} \\
-\boldsymbol{M}^{-1} \boldsymbol{K} & -\boldsymbol{M}^{-1} \boldsymbol{C}
\end{array}\right]\left\{\begin{array}{c}
\boldsymbol{X}(t) \\
\dot{\boldsymbol{X}}(t)
\end{array}\right\}+\left\{\begin{array}{c}
\mathbf{0} \\
\boldsymbol{M}^{-1} \boldsymbol{F}_{e}(t)
\end{array}\right\}+\left\{\begin{array}{c}
\mathbf{0} \\
\boldsymbol{M}^{-1} \boldsymbol{L} \boldsymbol{f}_{c}(t)
\end{array}\right\}
$$

Where, 0 and $I$ are respectively null matrix with all zero elements and identity matrix. Equation 27 can be simplified as,

$$
\dot{\boldsymbol{z}}(t)=\boldsymbol{A z}(t)+\boldsymbol{F}(t)
$$

Where,

$$
\begin{aligned}
& \boldsymbol{A}=\left[\begin{array}{cc}
\mathbf{0} & \boldsymbol{I} \\
-\boldsymbol{M}^{-1} \boldsymbol{K} & -\boldsymbol{M}^{-1} \boldsymbol{C}
\end{array}\right] \\
& \boldsymbol{F}(t)=\left\{\begin{array}{c}
\mathbf{0} \\
\boldsymbol{M}^{-1}\left(\boldsymbol{F}_{e}(t)+L f_{c}(t)\right)
\end{array}\right\}
\end{aligned}
$$

Equation 28 is the first-order linear differential equation, called as continuous state-space equation of motion. If $t_{0}$ represents the time when the initial displacement and velocity are given, the solution to above equation for any time $t>t_{0}$ can be written as,

$$
\boldsymbol{z}(t)=e^{\boldsymbol{A}\left(t-t_{0}\right)} \boldsymbol{z}\left(t_{0}\right)+e^{A t} \int_{t_{0}}^{t} e^{-A s} F(s) d s .
$$

To integrate the forcing function $F(s)$ in Equation 31, the method of numerical integration is used. If $t_{k+1}=t, t_{k}=t_{0}$, $\Delta t=t-t_{0}$, and $t_{k} \leq s \leq t_{k+1}$, using delta forcing function Equation 31 can be written as,

$$
\boldsymbol{z}_{k+1}=e^{A \Delta t} \boldsymbol{z}_{k}+\Delta t e^{-A t} \boldsymbol{F}
$$

Equation 32 leads to the displacement and velocity at time step $k+1$, while the acceleration is obtained through Equation 28. Time history analysis is carried out, and response quantities viz. displacements, base shear, overturning moment, and damper force are obtained.

For the elevated RC liquid storage tank with linear viscous dampers installed in its staging, the seismic response reduction is quantified as compared to the uncontrolled response, i.e., staging without dampers. Percentage reduction of the peak seismic response quantities for the cylindrical elevated RC tanks is calculated. For example, the percentage reduction in the convective displacement in $x$-direction $\left(x_{c}\right)$ is calculated as, 
$\%$ Reduction in $x_{c}=\left(\frac{\left(x_{c}\right)_{\mathrm{uc}}-\left(x_{c}\right)_{\mathrm{c}}}{\left(x_{c}\right)_{\mathrm{uc}}}\right) \times 100$

Where, $\left(x_{c}\right)_{\mathrm{uc}}$ is the response quantity without fluid viscous dampers, $\left(x_{c}\right)_{\mathrm{c}}$ is the response quantity with fluid viscous dampers installed in the staging of the elevated tank. Evidently, negative values of the percentage reduction signify seismic response magnification.

\section{Numerical Study}

The numerical study is conducted to evaluate the seismic response of the elevated liquid storage tanks installed with viscous dampers. A code has been written in MATLAB [31], for conducting time history analyses of the RC elevated liquid storage tank subjected to eight different real earthquake ground motions. Two types of tanks, with different slenderness, are considered. The slenderness of the cylindrical tanks is defined using aspect ratio, $S=H / R$, and two aspect ratios, viz. $S=0.5$ and 2.0 are considered. The influence of damping constant and nonlinear velocity exponent $(\alpha)$ is studied by varying $\alpha$ from 0 to 1 , increasing at an interval of 0.1 . Further, the effectiveness of using the three types of dampers, viz. linear viscous damper (LVD) and nonlinear viscous dampers, NLVD-I $(\alpha=0.5)$, and NLVD-II $(\alpha=0)$, with three configurations of placement of dampers in the staging of the elevated liquid storage tank is investigated.

Table 1 shows the geometric properties of the tank considered in the numerical study. The following are the geometric and material properties used in the numerical study: (i) height of liquid in the container $(H)$ is $5.05 \mathrm{~m}$ for tank full condition; inner diameter $(2 R)$ of the container is $5.06 \mathrm{~m}$; (ii) the contained liquid is considered as water with mass density $=1,000 \mathrm{~kg} / \mathrm{m}^{3}$; (iii) volume of the liquid is considered as $100 \%(S=2$, i.e., tank full) and $25 \%(S=0.5)$ of the tank capacity - excluding freeboard; (iv) for the RC staging, modulus of elasticity, $E=25 \times 10^{6} \mathrm{kN} / \mathrm{m}^{2}$, number of columns are four, the damping ratio of the RC staging, $\xi_{t}=5 \%$; (v) the damping ratio for convective mass, $\xi_{c}=$ $0.5 \%$; and (vi) two fluid viscous dampers, each with damping constant as, $C_{m d}=10 \mathrm{kN}-\mathrm{s} / \mathrm{m}, 40 \mathrm{kN}-\mathrm{s} / \mathrm{m}, 80 \mathrm{kN}-\mathrm{s} / \mathrm{m}$, $120 \mathrm{kN}-\mathrm{s} / \mathrm{m}$, and $140 \mathrm{kN}-\mathrm{s} / \mathrm{m}$ (with varying $\alpha$ ), with Configuration III placement of dampers, are installed in the staging of the RC elevated tank. The highest value of $C_{m d}$ is selected such that for the damper capacity does not exceed $130 \mathrm{kN}$, and the response of the tank is not increased. It is assumed that all dampers in the staging have the same damping constant and nonlinear exponent.

The dynamic properties of the tank modeled herein are presented in Table 2, which are obtained by conducting free vibration analysis. The details of the earthquake ground motion time histories considered are given in Table 3 . The coupled differential equations of motion for the system (Equation 28) are derived and solved by the state-space method. The seismic response quantities, viz. convective displacement $\left(x_{c}\right)$, rigid mass displacement $\left(x_{r}\right)$, displacements at the bracing levels of the RC staging $\left(x_{1}, x_{2}, \ldots, x_{p}\right)$, normalized base shear, $F_{b}=V_{b} / W$, overturning moment $\left(M_{o}\right)$ are obtained, each for two different aspect ratios of the tank. Here, $W=\left(M_{t}\right) g$ is the total weight of the tank, where $M_{t}$ is the total mass, considering bracing level masses, rigid mass, and convective mass. Further, seismic response of RC elevated liquid storage tank with fluid viscous dampers $\left(C_{m d}=80 \mathrm{kN}-\mathrm{s} / \mathrm{m}\right)$, LVD $(\alpha=1)$ and NLVD-I ( $\alpha=0.5)$, and NLVD-II $(\alpha=0)$, installed in the staging, is compared with the corresponding response of the tanks without dampers.

Table 1. Geometric properties of cylindrical RCC elevated liquid storage tank

\begin{tabular}{ccc}
\hline Sr. No. & Component & Dimension $(\mathbf{m m})$ \\
\hline 1. & Thickness of roof slab & 120 \\
2. & Thickness of tank wall $\left(t_{w}\right)$ & 200 \\
3. & Tank wall height including freeboard & 5300 \\
4. & Inner radius of the tank $(R)$ & 2530 \\
5. & Thickness of floor slab $\left(D_{f s}\right)$ & 250 \\
6. & Floor beam $\left(B \times D_{f b}\right)$ & $250 \times 600$ \\
7. & Bracing beams $(B \times D)$ & $400 \times 400$ \\
8. & Length of bracing beams $\left(L_{b}\right)$ & 3500 \\
9. & Column diameter & 500 \\
10. & Height of bottom panel $\left(L_{1}\right)$ & 2500 \\
11. & Height of intermediate panel $\left(L_{2}\right)$ & 3000 \\
12. & Height of top panel $\left(L_{3}\right)$ & 2500 \\
\hline
\end{tabular}


Table 2. Dynamic properties of RCC elevated liquid storage tank

\begin{tabular}{ccc|cc}
\hline & \multicolumn{2}{c|}{$\boldsymbol{S}=\mathbf{0 . 5}$} & \multicolumn{2}{c}{$\boldsymbol{S}=\mathbf{2 . 0}$} \\
\cline { 2 - 5 } $\boldsymbol{S}=\boldsymbol{H} / \boldsymbol{R}$ & \multicolumn{2}{c}{$\boldsymbol{H}_{\text {st }}=\mathbf{2 0} \mathbf{~ m}$} & \multicolumn{2}{c}{$\boldsymbol{H}_{\text {st }}=\mathbf{2 0} \mathbf{~ m}$} \\
\cline { 2 - 5 } & $\boldsymbol{T}(\mathbf{s})$ & $\boldsymbol{f}(\mathbf{H z})$ & $\boldsymbol{T}(\mathbf{s})$ & $\boldsymbol{f}(\mathbf{H z})$ \\
\hline Mode 1 & 5.06 & 0.20 & 3.68 & 0.27 \\
Mode 2 & 1.12 & 0.89 & 2.18 & 0.46 \\
Mode 3 & 0.57 & 1.76 & 0.58 & 1.73 \\
Mode 4 & 0.19 & 5.34 & 0.19 & 5.34 \\
Mode 5 & 0.11 & 9.19 & 0.11 & 9.19 \\
Mode 6 & 0.08 & 12.63 & 0.08 & 12.63 \\
Mode 7 & 0.07 & 15.22 & 0.07 & 15.22 \\
Mode 8 & 0.06 & 17.00 & 0.06 & 17.00 \\
Mode 9 & 0.05 & 21.33 & 0.05 & 21.33 \\
\hline$H_{r}(\mathrm{~m})$ & \multicolumn{3}{c|}{2.04} & \multicolumn{3}{c}{2.5} \\
\hline$H_{c}(\mathrm{~m})$ & \multicolumn{3}{c}{1.99} & \multicolumn{3}{c}{3.81} \\
\hline
\end{tabular}

Table 3. Details of earthquake ground acceleration time histories

\begin{tabular}{ccccccc}
\hline Sr. No. & Earthquake (Event Date) & $\begin{array}{c}\text { Recording } \\
\text { Station }\end{array}$ & Notation & Component & $\begin{array}{c}\text { Peak Ground } \\
\text { Acceleration }(\text { PGA })(\boldsymbol{g})\end{array}$ & $\begin{array}{c}\text { Number of Data } \\
\text { Points }(\Delta t)\end{array}$ \\
\hline 1. & Imperial Valley, $1940(18 / 05 / 1940)$ & El-Centro & Imperial Valley & S00E & 0.34 & $2688(0.02 \mathrm{~s})$ \\
2. & Tabas, 1978 (16/09/1978) & Tabas & Tabas & 344 & 0.93 & $2500(0.02 \mathrm{~s})$ \\
3. & Loma Prieta, 1989 (18/10/1989) & LPGC & Loma Prieta & 000 & 0.57 & $5001(0.005 \mathrm{~s})$ \\
4. & Turkey, 1992 (13/03/1992) & Erzican & Turkey & EW & 0.50 & $4156(0.005 \mathrm{~s})$ \\
5. & Northridge, 1994 (17/01/1994) & Sylmar County & Sylmar & 360 & 0.84 & $3000(0.02 \mathrm{~s})$ \\
6. & Kobe, 1995 (16/01/1995) & JMA & Kobe & 90 & 0.59 & $2400(0.02 \mathrm{~s})$ \\
7. & Chi-Chi,1999 (20/09/1999) & Chiayi-086 & Chi-Chi & N & 0.21 & $18000(0.005 \mathrm{~s})$ \\
8. & Bhuj, 2001 (26/01/2001) & Ahmedabad & Bhuj & N78E & 0.11 & $26706(0.005 \mathrm{~s})$ \\
\hline
\end{tabular}

\subsection{Influence of Nonlinear Exponent $\alpha$}

Figure 3 shows the effect of damping constant, nonlinear exponent, $\alpha$ on the response of the elevated liquid storage tanks $(S=2)$ subjected to Tabas, 1978 (0.93 g), Loma Prieta, 1989 (0.57 g), and Chi-Chi, 1999 (0.21 g) earthquakes. It is observed that the response of the tank reduces with a reduction in the nonlinear exponent, $1>\alpha>0$, is true only for fluid viscous dampers with low damping constant and when the RC tank is subjected to ground excitations of low PGA. It is noted that when the RC tank is installed with the NLVDs with $C_{m d} \geq 40 \mathrm{kN}-\mathrm{s} / \mathrm{m}$, the performance of the NLVDs, degrades with a reduction in the nonlinear exponent beyond a certain limit (indicated by a dotted line). It is also seen that the effect of damping constant is more in case of the RC tanks subjected to near field ground motions, than that of the far-field ground motions.

Further, it is observed that use of the NLVDs with higher damping constant $(120 \mathrm{kN}-\mathrm{s} / \mathrm{m})$ gives maximum reduction in base shear response at $\alpha=0.8$ (Tabas, 1978, PGA =0.93 g), $\alpha=0.3$ (Loma Prieta, 1989, PGA =0.57 g), and $\alpha=0.5$ (Chi-Chi, 1999, PGA $=0.21 \mathrm{~g}$ ). This behavior indicates that the response of the RC tank does not depend only upon the damper characteristics and PGA of the ground motion, but also on, site-specific characteristics of the ground motion. Promisingly, for lower damping ratio, $C_{m d}=10 \mathrm{kN}-\mathrm{s} / \mathrm{m}$, maximum base shear, overturning moment, and displacement response reduction is observed to be at $\alpha=0$. Hence, it is concluded that for low damping constants, as $\alpha$ changes from 1 to zero, the performance of the dampers enhances, and it is superior at $\alpha=0$. It is also interesting to note that for the tank subjected to ground motions of higher PGA, the use of the fluid viscous dampers with a higher value of damping constant, with $\alpha<0.6$, showed an increase in the displacement response. It is observed that when the elevated tanks subjected to high PGA events (Tabas, 1978) are installed with fluid viscous dampers in the staging of the tank, linear viscous dampers $(\alpha=1)$ with high damping constant are more advantageous; whereas for low PGA ground motions, NLVDs are beneficial. 

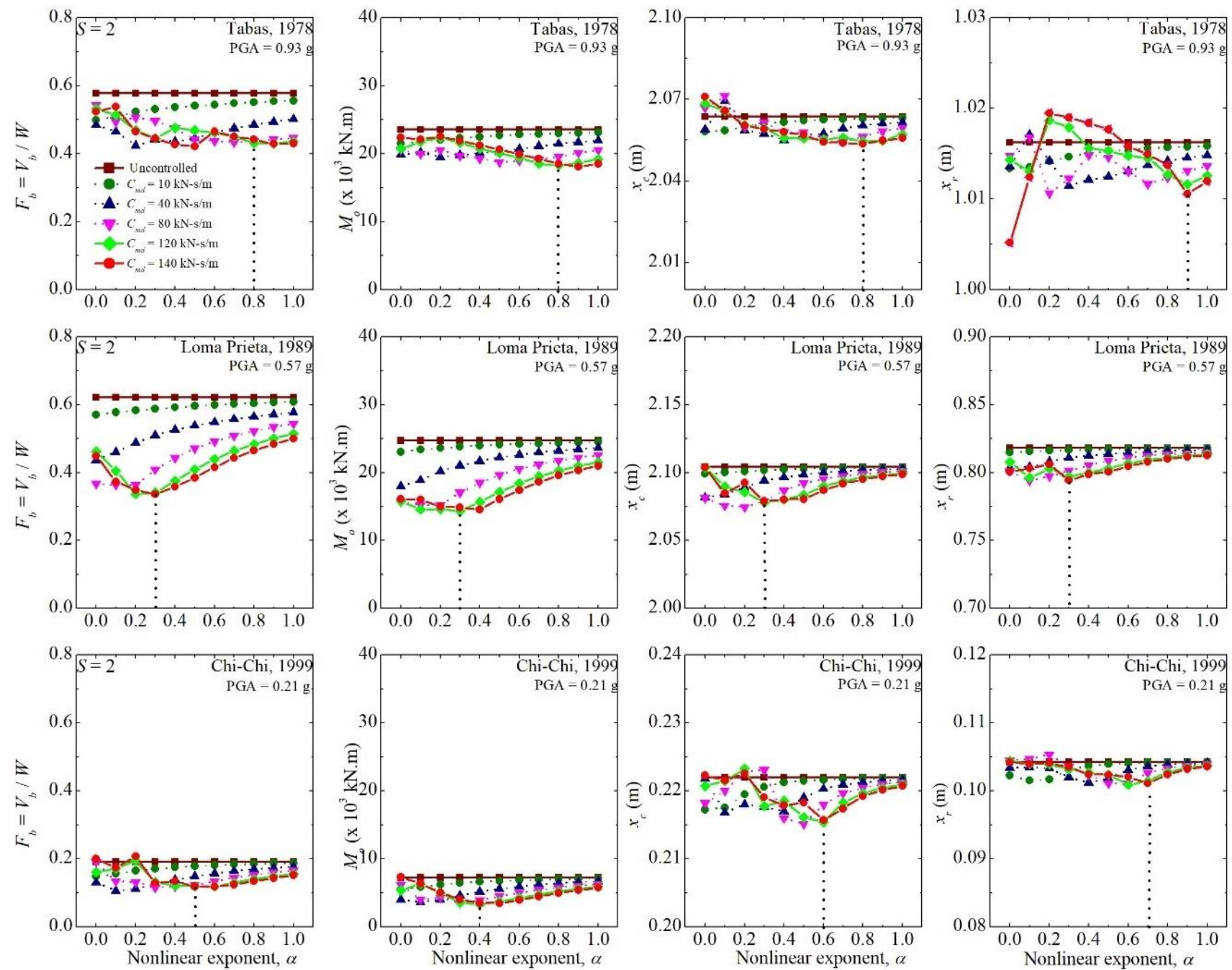

Figure 3. Effect of daming constant $C_{m d}$, and nonlinear exponent $\alpha$ on the response of the RC elevated liquid storage tanks $(S=2)$ installed with fluid viscous dampers, under Tabas, 1978, Loma Prieta, 1989, and Chi-Chi, 1999, earthquake

Figure 4 presents time variation of peak normalized base shear $\left(F_{b}\right)$, overturning moment $\left(M_{o}\right)$, convective mass displacement $\left(x_{c}\right)$ and rigid mass displacement $\left(x_{r}\right)$, for RC elevated liquid storage tank $(S=2)$ installed with fluid viscous dampers ; constant $C_{m d}=80 \mathrm{kN}-\mathrm{s} / \mathrm{m}(\alpha=1,0.5$, and 0$)$, and varying $C_{m d}$ as $40 \mathrm{kN}-\mathrm{s} / \mathrm{m}$ with $\alpha=0.5$ and $C_{m d}=$ $10 \mathrm{kN}-\mathrm{s} / \mathrm{m}$ with $\alpha=0$, under Loma Prieta, 1989 earthquake. The figure shows the effectiveness of the fluid viscous dampers for controlling the response of the RC elevated liquid storage tank. Further, the figure highlights the effectiveness of the NLVD ( $\alpha=0.5$ and $\alpha=0$ ) having lower damping constant. It is observed that the NLVD with lower damping constant gives a comparable reduction in response to that of LVD with higher damping constant. It is observed that the effectiveness of fluid viscous dampers, LVD $\left(C_{m d}=80 \mathrm{kN}-\mathrm{s} / \mathrm{m}, \alpha=1\right)$, NLVD $\left(C_{m d}=40 \mathrm{kN}-\mathrm{s} / \mathrm{m}, \alpha=\right.$ $0.5)$, and $\operatorname{NLVD}\left(C_{m d}=10 \mathrm{kN}-\mathrm{s} / \mathrm{m}, \alpha=0\right)$ is same in controlling the displacements at all the considered levels. Lower damping constant signifies the reduction in the size of the damper.

The response of the RC elevated liquid storage tank, with and without fluid viscous dampers (Configuration III) is presented in Table 4 and Table 5 for $S=0.5$ and $S=2$, respectively. From the table it is very interesting to note that NLVD-I $\left(C_{m d}=80 \mathrm{kN}-\mathrm{s} / \mathrm{m}, \alpha=0.5\right)$ is superior in controlling the displacement response in all the considered earthquakes than the LVD $\left(C_{m d}=80 \mathrm{kN}-\mathrm{s} / \mathrm{m}, \alpha=1\right)$ and NLVD-II $\left(C_{m d}=80 \mathrm{kN}-\mathrm{s} / \mathrm{m}, \alpha=0\right)$. Though the energy dissipation capacity of the NLVD-II is more than the LVD and NLVD-I, as seen in Figure 5. 

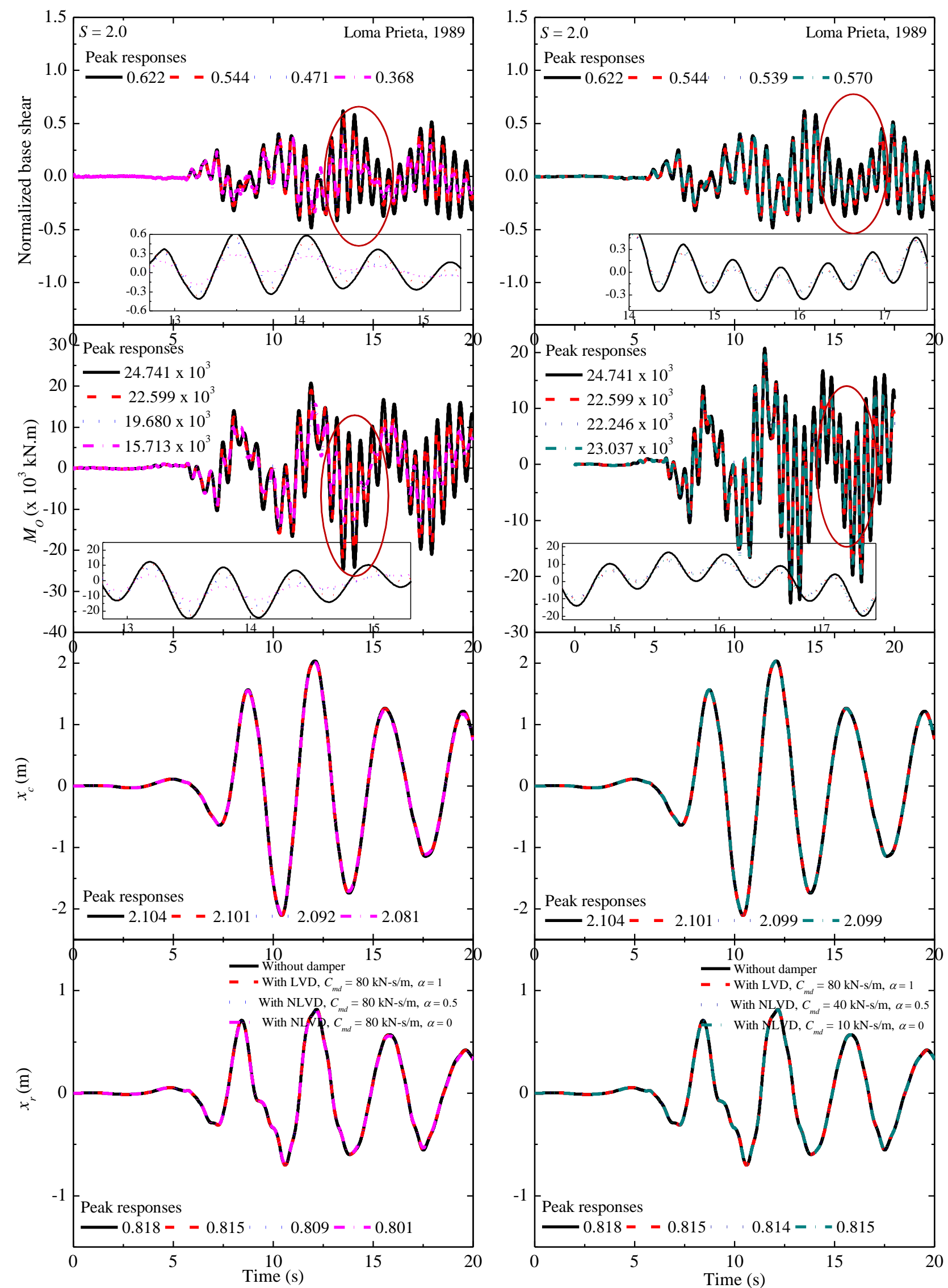

Figure 4. Time variation of response quantities, peak normalized base shear $\left(F_{b}\right)$, overturning moment $\left(M_{o}\right)$, convective mass displacement $\left(x_{c}\right)$ and rigid mass displacement $\left(x_{r}\right)$, for the RC elevated liquid storage tank $(S=2)$ installed with fluid viscous dampers; constant $C_{m d}=80 \mathrm{kN}-\mathrm{s} / \mathrm{m}(\alpha=1,0.5$, and 0$)$, and varying $C_{m d}\left(C_{m d}=40 \mathrm{kN}-\mathrm{s} / \mathrm{m}\right.$ with $\alpha=0.5$, and $C_{m d}=10$ kN-s/m with $\alpha=0)$, under Loma Prieta, 1989 earthquake. 

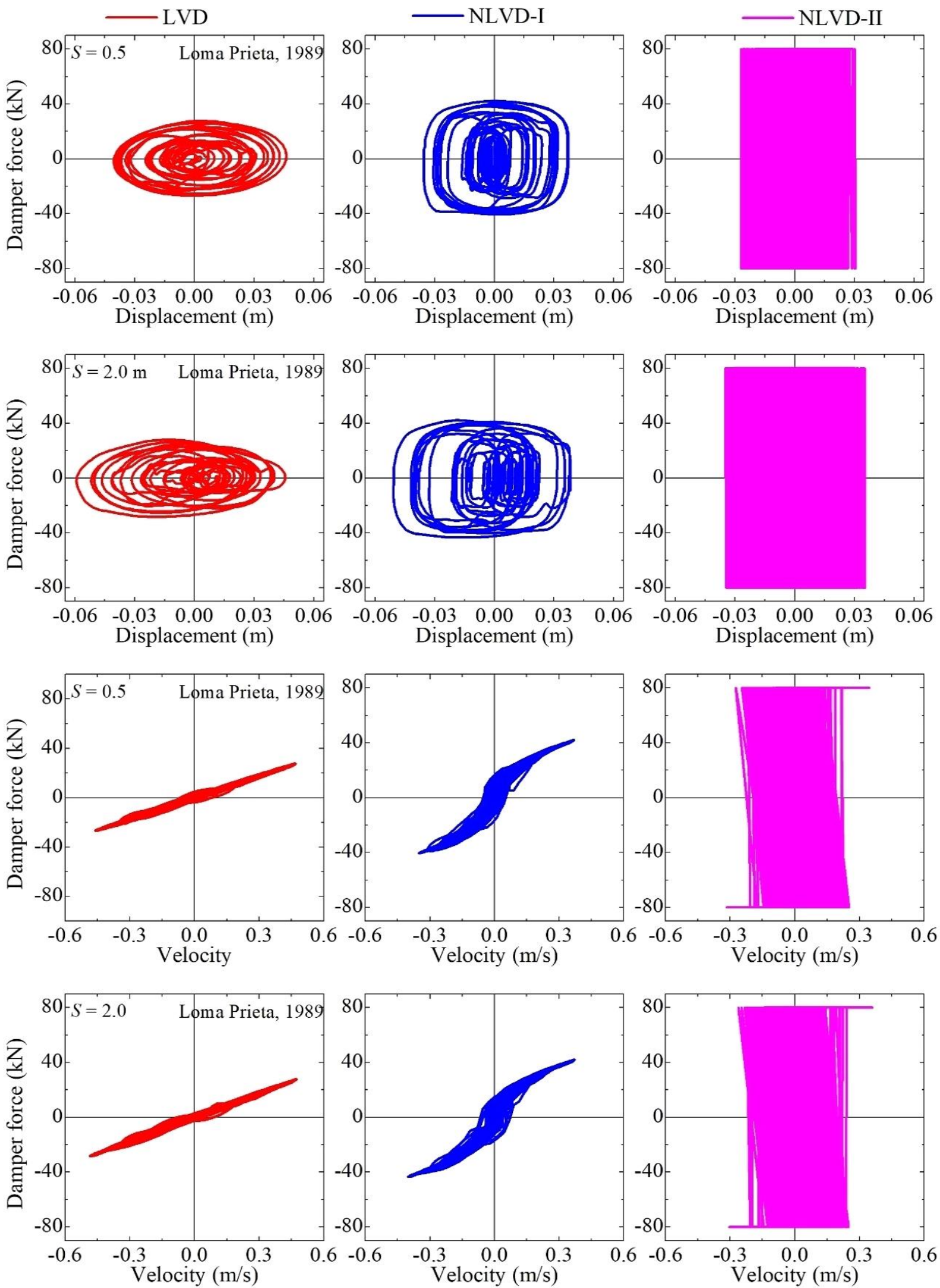

Figure 5. Force displacement loops for linear and nonlinear viscous dampers (LVD, NLVD-I, and NLVD-II) installed in RC elevated liquid storage tank under Loma Prieta, 1989 earthquake

\subsection{Displacement-damper Force Relationship}

Figure 5 shows the relationship between the damper force and displacement obtained for RC elevated liquid storage tank, installed with fluid viscous dampers (LVD, NLVD-I, and NLVD-II), under Loma Prieta, 1989 earthquake. The figure clearly portrays the energy dissipation characteristics of the dampers. For linear viscous damper (LVD), 
damping force is directly proportional to the displacement; for NLVD-I the force-displacement is slightly nonlinear; while for NLVD-II the force-displacement relation is rectangular, as seen in case of friction dampers. Further, the bigger size of the force-deformation loop signifies the more energy dissipation. From Figure 5, it is clear that NLVDs dissipate more energy than the LVDs, highlighting the efficiency of nonlinear viscous dampers over linear viscous dampers. As the dampers are installed in the staging of the elevated tank, the present approach of considering a multidegree freedom system for staging is a powerful tool for assessing the performance of the tank installed with dampers.

Table 4. Peak values of bracing level displacement responses and the damper forces in the RC elevated liquid storage tank $(S=0.5)$ installed with the fluid viscous dampers (LVD, NLVD-I, and NLVD-II): Configuration III

\begin{tabular}{|c|c|c|c|c|c|c|c|c|c|c|c|c|c|c|c|}
\hline Earthquake & $\begin{array}{l}\text { Response } \\
\text { quantity }\end{array}$ & $\begin{array}{l}x_{1} \\
(\mathbf{m})\end{array}$ & $\begin{array}{c}x_{2} \\
(\mathbf{m})\end{array}$ & $x_{3}(\mathbf{m})$ & $\begin{array}{c}x_{4} \\
(\mathbf{m})\end{array}$ & $\begin{array}{c}x_{5} \\
(\mathbf{m})\end{array}$ & $\begin{array}{c}x_{6} \\
(\mathbf{m})\end{array}$ & $x_{7}(\mathbf{m})$ & $\begin{array}{l}F_{D 1} \\
(\mathbf{k N})\end{array}$ & $\begin{array}{c}F_{D 2} \\
(\mathbf{k N})\end{array}$ & $\begin{array}{l}F_{D 3} \\
(\mathbf{k N})\end{array}$ & $\begin{array}{l}F_{D 4} \\
(\mathbf{k N})\end{array}$ & $\begin{array}{l}F_{D 5} \\
(\mathbf{k N})\end{array}$ & $\begin{array}{l}F_{D 6} \\
(\mathbf{k N})\end{array}$ & $\begin{array}{c}F_{D 7} \\
(\mathbf{k N})\end{array}$ \\
\hline \multirow{4}{*}{$\begin{array}{c}\text { Imperial } \\
\text { Valley, } 1940\end{array}$} & Without damper & 0.01 & 0.03 & 0.05 & 0.06 & 0.08 & 0.09 & 0.09 & --- & --- & --- & --- & --- & --- & --- \\
\hline & With LVD & 0.01 & 0.02 & 0.04 & 0.06 & 0.07 & 0.08 & 0.08 & 4.21 & 14.15 & 12.12 & 12.40 & 11.90 & 11.23 & 0.67 \\
\hline & With NLVD-I & 0.01 & 0.02 & 0.04 & 0.05 & 0.06 & 0.07 & 0.08 & 31.42 & 49.35 & 47.71 & 48.81 & 46.52 & 47.68 & 27.95 \\
\hline & With NLVD-II & 0.01 & 0.03 & 0.05 & 0.07 & 0.08 & 0.09 & 0.09 & 80.00 & 80.00 & 80.00 & 80.00 & 80.00 & 80.00 & 80.00 \\
\hline \multirow{4}{*}{ Tabas, 1978} & Without damper & 0.01 & 0.05 & 0.08 & 0.11 & 0.15 & 0.18 & 0.18 & --- & --- & --- & --- & --- & --- & --- \\
\hline & With LVD & 0.01 & 0.04 & 0.08 & 0.11 & 0.14 & 0.16 & 0.16 & 13.58 & 44.31 & 29.58 & 27.71 & 28.30 & 28.25 & 2.02 \\
\hline & With NLVD-I & 0.01 & 0.04 & 0.07 & 0.10 & 0.12 & 0.14 & 0.14 & 36.85 & 57.09 & 50.32 & 49.51 & 51.48 & 49.50 & 29.30 \\
\hline & With NLVD-II & 0.01 & 0.04 & 0.08 & 0.10 & 0.13 & 0.15 & 0.15 & 80.00 & 80.00 & 80.00 & 80.00 & 80.00 & 80.00 & 80.00 \\
\hline \multirow{4}{*}{$\begin{array}{c}\text { Loma Prieta, } \\
1989\end{array}$} & Without damper & 0.02 & 0.06 & 0.10 & 0.13 & 0.16 & 0.18 & 0.18 & --- & --- & --- & --- & --- & --- & --- \\
\hline & With LVD & 0.01 & 0.05 & 0.08 & 0.11 & 0.13 & 0.15 & 0.15 & 10.02 & 27.69 & 25.59 & 22.67 & 18.60 & 15.83 & 2.46 \\
\hline & With NLVD-I & 0.01 & 0.04 & 0.06 & 0.08 & 0.10 & 0.12 & 0.12 & 25.31 & 42.13 & 40.61 & 39.03 & 36.85 & 35.03 & 13.12 \\
\hline & With NLVD-II & 0.01 & 0.03 & 0.05 & 0.06 & 0.08 & 0.09 & 0.09 & 80.00 & 80.00 & 80.00 & 80.00 & 80.00 & 80.00 & 80.00 \\
\hline \multirow{4}{*}{$\begin{array}{c}\text { Turkey, } \\
1992\end{array}$} & Without damper & 0.01 & 0.03 & 0.05 & 0.07 & 0.08 & 0.09 & 0.10 & --- & --- & --- & --- & --- & --- & --- \\
\hline & With LVD & 0.01 & 0.03 & 0.04 & 0.06 & 0.07 & 0.08 & 0.08 & 5.11 & 14.07 & 13.25 & 12.28 & 12.61 & 11.18 & 1.51 \\
\hline & With NLVD-I & 0.01 & 0.02 & 0.03 & 0.04 & 0.04 & 0.05 & 0.05 & 16.95 & 28.59 & 27.39 & 27.96 & 26.48 & 24.07 & 10.56 \\
\hline & With NLVD-II & 0.01 & 0.02 & 0.03 & 0.04 & 0.05 & 0.06 & 0.06 & 80.00 & 80.00 & 80.00 & 80.00 & 80.00 & 80.00 & 80.00 \\
\hline \multirow{4}{*}{$\begin{array}{c}\text { Sylmar, } \\
1994\end{array}$} & Without damper & 0.01 & 0.05 & 0.08 & 0.11 & 0.14 & 0.16 & 0.16 & --- & -- & --- & --- & --- & --- & --- \\
\hline & With LVD & 0.01 & 0.04 & 0.07 & 0.10 & 0.13 & 0.15 & 0.15 & 9.12 & 29.43 & 22.23 & 20.70 & 19.47 & 18.30 & 1.19 \\
\hline & With NLVD-I & 0.01 & 0.04 & 0.07 & 0.10 & 0.12 & 0.14 & 0.14 & 32.95 & 54.46 & 49.74 & 51.39 & 50.68 & 49.87 & 28.41 \\
\hline & With NLVD-II & 0.02 & 0.04 & 0.07 & 0.10 & 0.13 & 0.15 & 0.16 & 80.00 & 80.00 & 80.00 & 80.00 & 80.00 & 80.00 & 80.00 \\
\hline \multirow{4}{*}{ Kobe, 1995} & Without damper & 0.01 & 0.04 & 0.07 & 0.10 & 0.12 & 0.14 & 0.14 & -- & -- & --- & -- & -- & --- & --- \\
\hline & With LVD & 0.01 & 0.04 & 0.06 & 0.09 & 0.10 & 0.12 & 0.12 & 6.58 & 22.85 & 18.49 & 16.90 & 13.71 & 12.20 & 0.81 \\
\hline & With NLVD-I & 0.01 & 0.03 & 0.06 & 0.08 & 0.10 & 0.11 & 0.11 & 34.34 & 53.16 & 49.59 & 50.35 & 49.11 & 47.43 & 28.34 \\
\hline & With NLVD-II & 0.01 & 0.04 & 0.07 & 0.09 & 0.11 & 0.13 & 0.14 & 80.00 & 80.00 & 80.00 & 80.00 & 80.00 & 80.00 & 80.00 \\
\hline \multirow{4}{*}{$\begin{array}{l}\text { Chi-Chi, } \\
1999\end{array}$} & Without damper & 0.01 & 0.02 & 0.04 & 0.05 & 0.07 & 0.08 & 0.08 & --- & --- & --- & --- & --- & --- & --- \\
\hline & With LVD & 0.01 & 0.02 & 0.03 & 0.04 & 0.05 & 0.06 & 0.06 & 4.48 & 12.24 & 11.10 & 9.76 & 8.17 & 6.34 & 0.89 \\
\hline & With NLVD-I & 0.00 & 0.01 & 0.02 & 0.03 & 0.03 & 0.04 & 0.04 & 14.48 & 25.22 & 23.58 & 22.24 & 20.29 & 18.69 & 10.93 \\
\hline & With NLVD-II & 0.01 & 0.02 & 0.03 & 0.04 & 0.05 & 0.06 & 0.06 & 80.00 & 80.00 & 80.00 & 80.00 & 80.00 & 80.00 & 80.00 \\
\hline \multirow{4}{*}{ Bhuj, 2001} & Without damper & 0.00 & 0.01 & 0.02 & 0.02 & 0.03 & 0.03 & 0.03 & --- & -- & --- & --- & -- & --- & -- \\
\hline & With LVD & 0.00 & 0.01 & 0.01 & 0.02 & 0.02 & 0.03 & 0.03 & 1.72 & 4.08 & 3.78 & 3.68 & 3.52 & 3.00 & 0.47 \\
\hline & With NLVD-I & 0.00 & 0.01 & 0.01 & 0.01 & 0.02 & 0.02 & 0.02 & 11.59 & 15.50 & 15.87 & 13.54 & 15.92 & 13.14 & 9.48 \\
\hline & With NLVD-II & 0.00 & 0.01 & 0.02 & 0.02 & 0.03 & 0.03 & 0.03 & 80.00 & 80.00 & 80.00 & 80.00 & 80.00 & 80.00 & 80.00 \\
\hline
\end{tabular}


Table 5. Peak values of bracing level displacement responses and the damper forces in the $\mathrm{RC}$ elevated liquid storage tank $(\mathrm{S}=\mathbf{2 . 0}$ ) installed with the fluid viscous dampers (LVD, NLVD-I, and NLVD-II): Configuration III

\begin{tabular}{|c|c|c|c|c|c|c|c|c|c|c|c|c|c|c|c|}
\hline Earthquake & $\begin{array}{l}\text { Response } \\
\text { quantity }\end{array}$ & $\begin{array}{c}x_{1} \\
(\mathbf{m})\end{array}$ & $\begin{array}{c}x_{2} \\
(\mathbf{m})\end{array}$ & $x_{3}(\mathrm{~m})$ & $\begin{array}{c}x_{4} \\
(\mathbf{m})\end{array}$ & $\begin{array}{c}x_{5} \\
(\mathbf{m})\end{array}$ & $\begin{array}{c}x_{6} \\
(\mathbf{m})\end{array}$ & $x_{7}(\mathbf{m})$ & $\begin{array}{c}F_{D 1} \\
(\mathbf{k N})\end{array}$ & $\begin{array}{c}F_{D 2} \\
(\mathbf{k N})\end{array}$ & $\begin{array}{c}F_{D 3} \\
(\mathbf{k N})\end{array}$ & $\begin{array}{c}F_{D 4} \\
(\mathbf{k N})\end{array}$ & $\begin{array}{c}F_{D 5} \\
(\mathbf{k N})\end{array}$ & $\begin{array}{c}F_{D 6} \\
(\mathbf{k N})\end{array}$ & $\begin{array}{c}F_{D 7} \\
(\mathbf{k N})\end{array}$ \\
\hline \multirow{4}{*}{$\begin{array}{c}\text { Imperial } \\
\text { Valley, } 1940\end{array}$} & Without damper & 0.01 & 0.03 & 0.05 & 0.07 & 0.08 & 0.09 & 0.09 & --- & --- & --- & --- & --- & --- & --- \\
\hline & With LVD & 0.01 & 0.03 & 0.04 & 0.06 & 0.07 & 0.08 & 0.08 & 4.52 & 14.92 & 12.93 & 13.13 & 12.63 & 12.11 & 0.78 \\
\hline & With NLVD-I & 0.01 & 0.03 & 0.04 & 0.06 & 0.07 & 0.08 & 0.08 & 31.21 & 49.89 & 47.61 & 49.28 & 46.50 & 48.28 & 27.95 \\
\hline & With NLVD-II & 0.01 & 0.03 & 0.05 & 0.06 & 0.07 & 0.08 & 0.08 & 80.00 & 80.00 & 80.00 & 80.00 & 80.00 & 80.00 & 80.00 \\
\hline \multirow{4}{*}{ Tabas, 1978} & Without damper & 0.02 & 0.06 & 0.10 & 0.14 & 0.18 & 0.21 & 0.22 & --- & --- & --- & --- & --- & --- & --- \\
\hline & With LVD & 0.01 & 0.05 & 0.09 & 0.12 & 0.16 & 0.18 & 0.19 & 12.89 & 44.74 & 30.65 & 29.12 & 29.98 & 30.26 & 2.20 \\
\hline & With NLVD-I & 0.01 & 0.05 & 0.08 & 0.11 & 0.14 & 0.17 & 0.17 & 38.44 & 56.94 & 50.53 & 49.47 & 51.64 & 50.51 & 29.24 \\
\hline & With NLVD-II & 0.02 & 0.05 & 0.09 & 0.13 & 0.16 & 0.18 & 0.19 & 80.00 & 80.00 & 80.00 & 80.00 & 80.00 & 80.00 & 80.00 \\
\hline \multirow{4}{*}{$\begin{array}{c}\text { Loma Prieta, } \\
1989\end{array}$} & Without damper & 0.02 & 0.07 & 0.11 & 0.15 & 0.19 & 0.22 & 0.22 & --- & --- & --- & --- & --- & --- & --- \\
\hline & With LVD & 0.02 & 0.06 & 0.10 & 0.14 & 0.17 & 0.20 & 0.20 & 10.51 & 28.25 & 25.86 & 22.85 & 19.49 & 17.42 & 2.75 \\
\hline & With NLVD-I & 0.02 & 0.05 & 0.09 & 0.12 & 0.15 & 0.17 & 0.17 & 26.25 & 43.44 & 41.22 & 39.02 & 37.51 & 35.73 & 13.64 \\
\hline & With NLVD-II & 0.01 & 0.04 & 0.06 & 0.08 & 0.10 & 0.12 & 0.13 & 80.00 & 80.00 & 80.00 & 80.00 & 80.00 & 80.00 & 80.00 \\
\hline \multirow{4}{*}{ Turkey, 1992} & Without damper & 0.01 & 0.04 & 0.06 & 0.08 & 0.10 & 0.12 & 0.12 & --- & --- & --- & --- & --- & --- & --- \\
\hline & With LVD & 0.01 & 0.03 & 0.05 & 0.07 & 0.09 & 0.10 & 0.10 & 6.51 & 17.90 & 14.99 & 15.44 & 15.62 & 14.09 & 2.14 \\
\hline & With NLVD-I & 0.01 & 0.02 & 0.04 & 0.05 & 0.06 & 0.07 & 0.08 & 19.19 & 32.59 & 30.89 & 31.59 & 30.72 & 29.20 & 11.24 \\
\hline & With NLVD-II & 0.01 & 0.03 & 0.04 & 0.06 & 0.07 & 0.08 & 0.09 & 80.00 & 80.00 & 80.00 & 80.00 & 80.00 & 80.00 & 80.00 \\
\hline \multirow{4}{*}{ Sylmar, 1994} & Without damper & 0.01 & 0.04 & 0.07 & 0.09 & 0.12 & 0.14 & 0.14 & --- & -- & --- & --- & -- & -- & --- \\
\hline & With LVD & 0.01 & 0.03 & 0.06 & 0.08 & 0.10 & 0.12 & 0.13 & 8.55 & 28.56 & 23.30 & 23.16 & 21.77 & 20.87 & 1.41 \\
\hline & With NLVD-I & 0.01 & 0.03 & 0.05 & 0.08 & 0.10 & 0.12 & 0.12 & 33.93 & 53.63 & 48.58 & 50.99 & 52.11 & 48.50 & 28.84 \\
\hline & With NLVD-II & 0.01 & 0.04 & 0.06 & 0.09 & 0.11 & 0.13 & 0.14 & 80.00 & 80.00 & 80.00 & 80.00 & 80.00 & 80.00 & 80.00 \\
\hline \multirow{4}{*}{ Kobe, 1995} & Without damper & 0.01 & 0.04 & 0.07 & 0.09 & 0.11 & 0.12 & 0.13 & --- & --- & --- & --- & --- & --- & --- \\
\hline & With LVD & 0.01 & 0.04 & 0.06 & 0.09 & 0.10 & 0.12 & 0.12 & 7.71 & 23.28 & 18.49 & 17.29 & 14.81 & 12.86 & 0.58 \\
\hline & With NLVD-I & 0.01 & 0.04 & 0.06 & 0.08 & 0.10 & 0.11 & 0.11 & 35.07 & 52.39 & 50.77 & 48.69 & 49.55 & 46.99 & 28.15 \\
\hline & With NLVD-II & 0.01 & 0.05 & 0.07 & 0.10 & 0.12 & 0.13 & 0.13 & 80.00 & 80.00 & 80.00 & 80.00 & 80.00 & 80.00 & 80.00 \\
\hline \multirow{4}{*}{$\begin{array}{c}\text { Chi-Chi, } \\
1999\end{array}$} & Without damper & 0.01 & 0.02 & 0.04 & 0.05 & 0.06 & 0.07 & 0.07 & -- & -- & -- & --- & -- & --- & -- \\
\hline & With LVD & 0.01 & 0.02 & 0.03 & 0.04 & 0.05 & 0.06 & 0.06 & 4.24 & 11.64 & 10.88 & 9.86 & 8.35 & 6.54 & 0.92 \\
\hline & With NLVD-I & 0.00 & 0.01 & 0.02 & 0.03 & 0.04 & 0.04 & 0.04 & 14.71 & 26.50 & 24.86 & 23.69 & 21.91 & 20.26 & 10.27 \\
\hline & With NLVD-II & 0.01 & 0.02 & 0.03 & 0.04 & 0.05 & 0.06 & 0.06 & 80.00 & 80.00 & 80.00 & 80.00 & 80.00 & 80.00 & 80.00 \\
\hline \multirow{4}{*}{ Bhuj, 2001} & Without damper & 0.00 & 0.01 & 0.02 & 0.02 & 0.03 & 0.03 & 0.03 & --- & --- & --- & --- & --- & --- & --- \\
\hline & With LVD & 0.00 & 0.01 & 0.01 & 0.02 & 0.02 & 0.03 & 0.03 & 1.58 & 4.25 & 3.91 & 3.64 & 3.26 & 2.74 & 0.42 \\
\hline & With NLVD-I & 0.00 & 0.01 & 0.01 & 0.01 & 0.02 & 0.02 & 0.02 & 10.94 & 14.92 & 16.74 & 13.10 & 16.56 & 12.92 & 9.64 \\
\hline & With NLVD-II & 0.00 & 0.01 & 0.02 & 0.02 & 0.03 & 0.03 & 0.03 & 80.00 & 80.00 & 80.00 & 80.00 & 80.00 & 80.00 & 80.00 \\
\hline
\end{tabular}

\subsection{Effect of Placement of Damper}

Figures 6 and 7 present peak percentage reduction in base shear and the overturning moment when the RC elevated tank is installed with the fluid viscous dampers ( LVD, $\alpha=1$, NLVD-I, $\alpha=0.5$ and NLVD-II, $\alpha=0$ ), for $S=0.5$ and $S$ $=2$, respectively, subjected to eight different earthquake ground motions (refer Table 1 for earthquake numbers). Furthermore, figures show the variation on maximum damper force induced at different levels in the elevated tank, with Configuration I, Configuration II and Configuration III placement of fluid viscous dampers. From figures, it is observed that with the installation of NLVDs in the staging of the tank, Configuration I and Configuration II are more effective in reducing the base shear response of the tank, than the Configuration III. However, the damper force induced in the damper is more in Configuration III. Maximum reduction of $80 \%$ and $75 \%$ in base shear and overturning moment, respectively, is achieved with the installation of NLVDs in the RC elevated liquid storage tank ( $S$ $=0.5$ ). Further, the peak response reduction of $70 \%$ and $65 \%$, in base shear response and overturning moment response is achieved with NLVDs $(S=2.0)$.

It is observed from the results (Figures 3, 6 and 7 ) that the dampers with $0<\alpha \leq 1$ help to dissipate the seismic energy more effectively, without contributing towards increasing stiffness; hence, bracing level displacements, rigid 
mass displacement, and convective displacement response are effectively reduced by installing fluid viscous damper with $0<\alpha \leq 1$, under all considered earthquakes. However, as far as the base shear response reduction is concerned, it is observed that the response reduction using the fluid viscous dampers with $\alpha=0$ and $\alpha=0.5$ is more, as compared to that with $\alpha=1$. However, a marginal increase in either (or both) of the base shear and overturning moment response is observed with the NLVD-II $(\alpha=0)$, Configuration III in Imperial Valley, 1940, Sylmar, 1994, Kobe, 1995, Chi-Chi, 1999 and Bhuj, 2001, earthquakes, which is attributed towards the increased stiffness imparted. Further, it is noticed that with the use of fluid viscous dampers, the base shear is substantially reduced under all considered earthquakes. It is observed that typically all the LVDs and NLVDs with appropriate nonlinear exponent $\alpha$ reduce the response of the $\mathrm{RC}$ tank; however, the reduction with the NLVDs $(\alpha=0$ and 0.5$)$ is more than that of the $\operatorname{LVD}(\alpha=1)$.
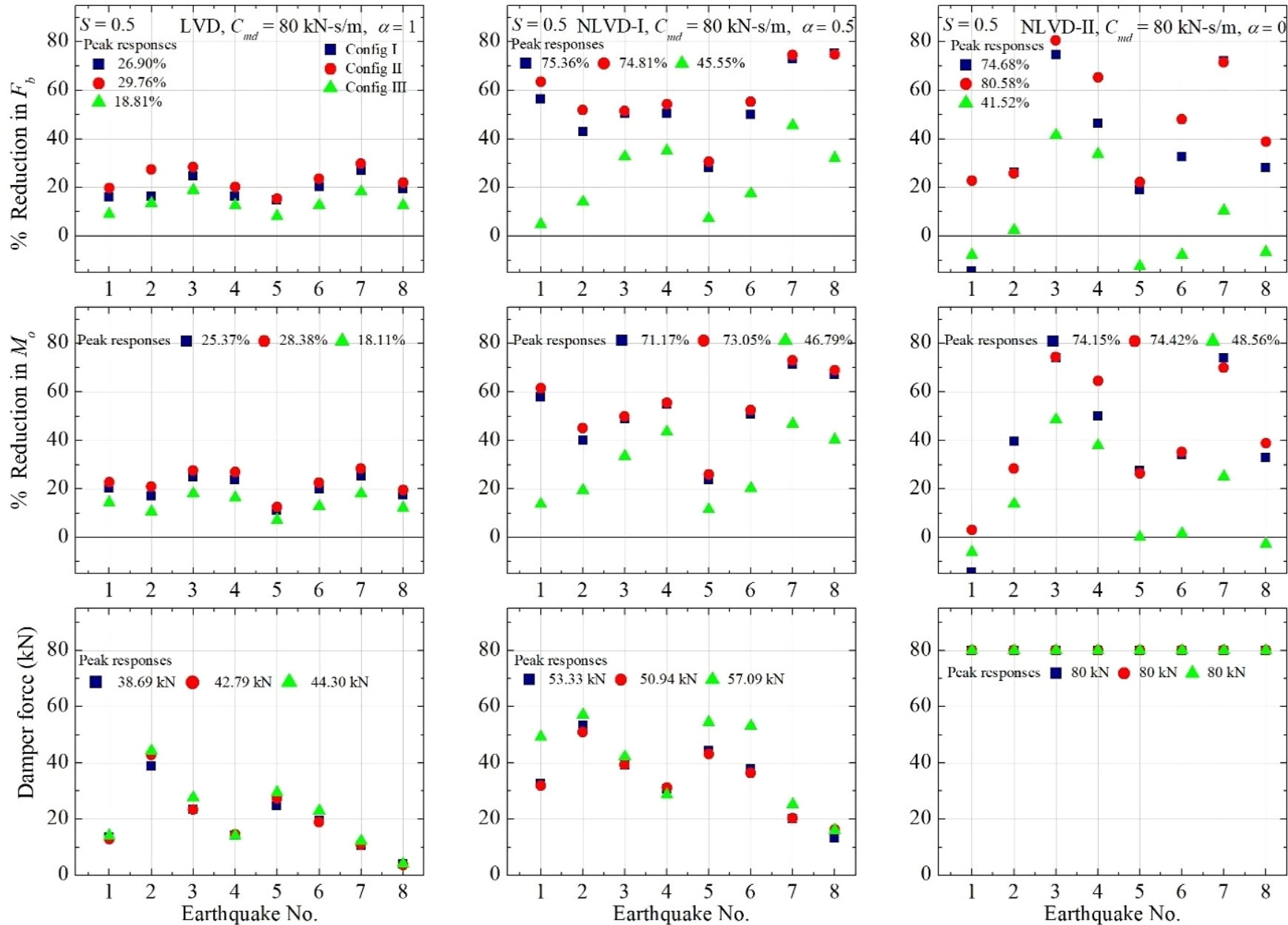

Figure 6. \% Reduction in peak seismic response quantities, normalized base shear $\left(F_{b}\right)$, overturning moment $\left(M_{o}\right)$, and the peak damper force induced for the RC elevated liquid storage tank $(S=0.5)$ installed with the LVD, and NLVD $(\alpha=0.5$ and 0), under different earthquakes.

Figure 8 presents storey shears, overturning moment, and damper force induced at different levels in the elevated tank, with and without fluid viscous dampers (Configuration I, Configuration II, and Configuration III), under Loma Prieta, 1989 earthquake. It is observed that the use of the fluid viscous dampers has helped in reducing the seismic storey shear substantially. Similarly, remarkable reduction in the overturning moment is achieved with the help of the fluid viscous dampers. Further, it is observed that the force induced in the dampers at various levels along the height of the staging of the tank varies. Moreover, it is observed from Figure 8 that at all levels and in all considered placement of dampers, the damper force induced in the NLVD-I is less than that of LVD and NLVD-II. It is a fact that nonlinear viscous dampers absorb high velocity shocks with less damper force. Whereas, in case the NLVD-IIs the damper force is constant for all considered placement configurations. This is because, in case of the NLVD-IIs, with nonlinear exponent, $\alpha=0$, the damper force is no longer proportional to the velocity and is a function of damping constant only. Additionally, it is very interesting to note that the damper force induced in the first and second level dampers is less than that of the dampers installed in the intermediate panels. Such effectiveness of the dampers based on the nonlinear exponent $(\alpha)$ is anticipated due to the variation of velocities of the masses along the height of the structure. 

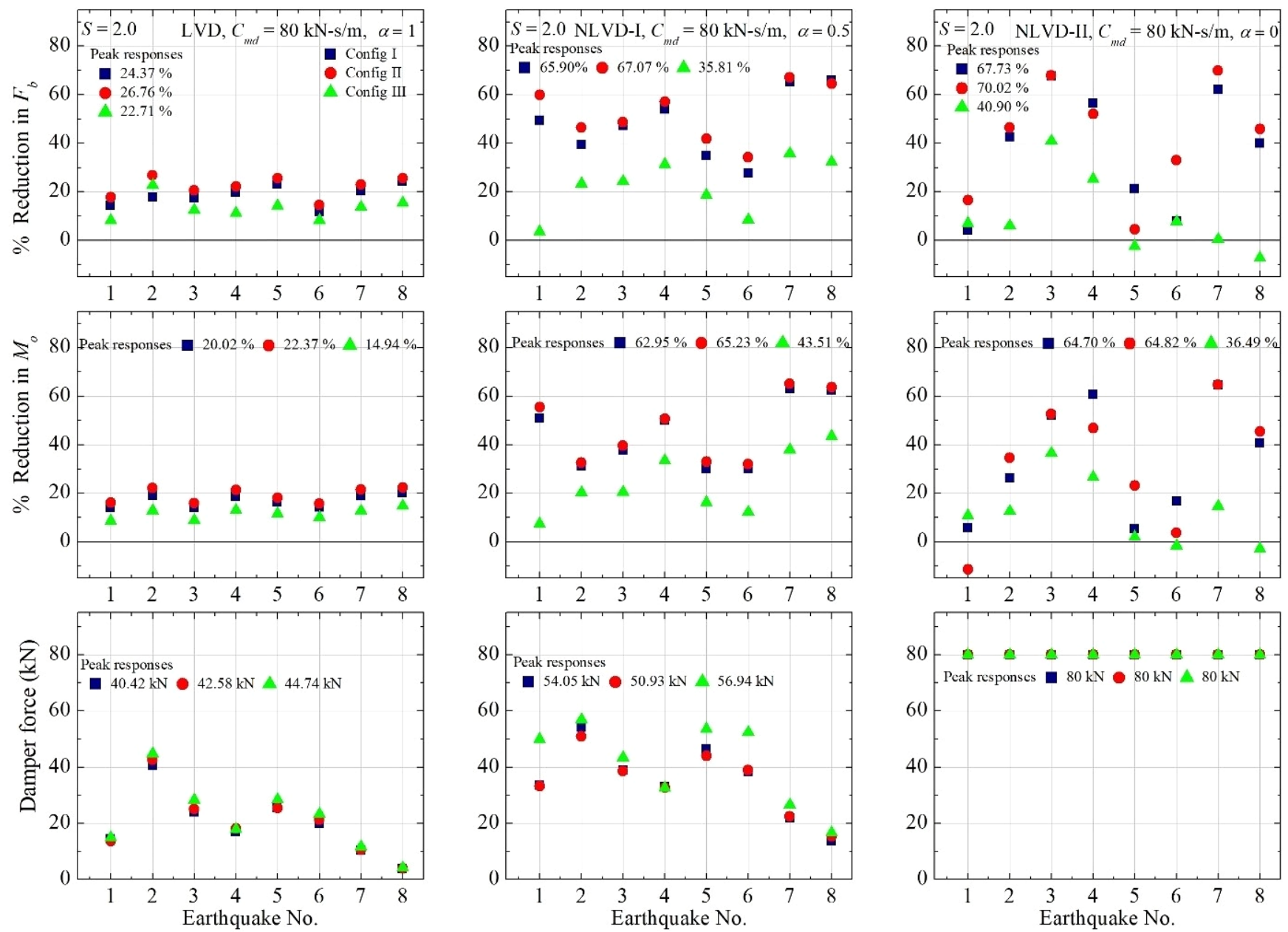

Figure 7. $\%$ Reduction in peak seismic response quantities, normalized base shear $\left(F_{b}\right)$, overturning moment $\left(M_{o}\right)$ and the peak damper force induced for the RC elevated liquid storage tank $(S=2.0)$ installed with the LVD, and NLVD $(\alpha=0.5$ and 0), under different earthquakes.

Figure 9 presents \% Reduction in rigid mass displacement $\left(x_{r}\right)$, and convective displacement $\left(x_{c}\right)$ for the RC elevated liquid storage tank $(S=0.5$ and $S=2.0)$ installed with the LVD, and NLVD $(\alpha=0.5$ and 0$)$, under different earthquakes. It is observed from the figure that the maximum reduction of rigid mass displacement is $38 \%(S=0.5$, NLVD-I, Configuration I), and convective displacement is reduced by $9 \%(S=2.0$, NLVD-I, Configuration I). Configuration II also has a comparable reduction in displacement response, whereas Configuration III reported the least displacement response reduction. Additionally, it is observed that the NLVD-I is superior in controlling displacement response than the other considered fluid viscous dampers (LVD and NLVD-II). Further, a marginal increase in the displacement response is observed for the RC elevated tank installed with LVD and NLVD-II (Configuration I, Configuration II and Configuration III). Promisingly, no such increase is observed for NLVD-I (Configuration I and Configuration II). 

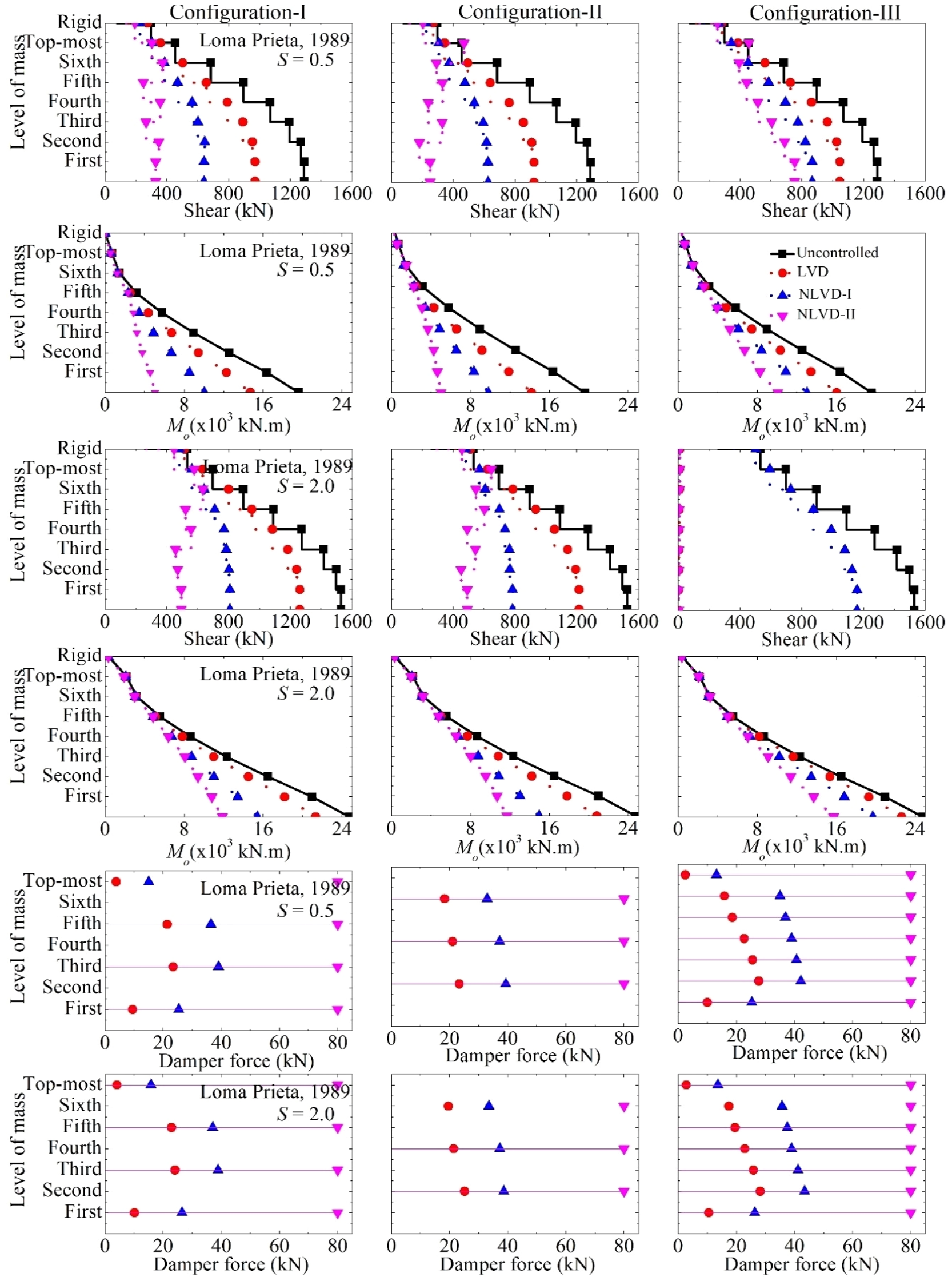

Figure 8. Peak storey shear, overturning moment, and the damper forces, induced at the different level masses of RC elevated water tank with and without fluid viscous dampers (Configuration I, Configuration II, and Configuration III), under Loma Prieta, 1989 earthquake. 

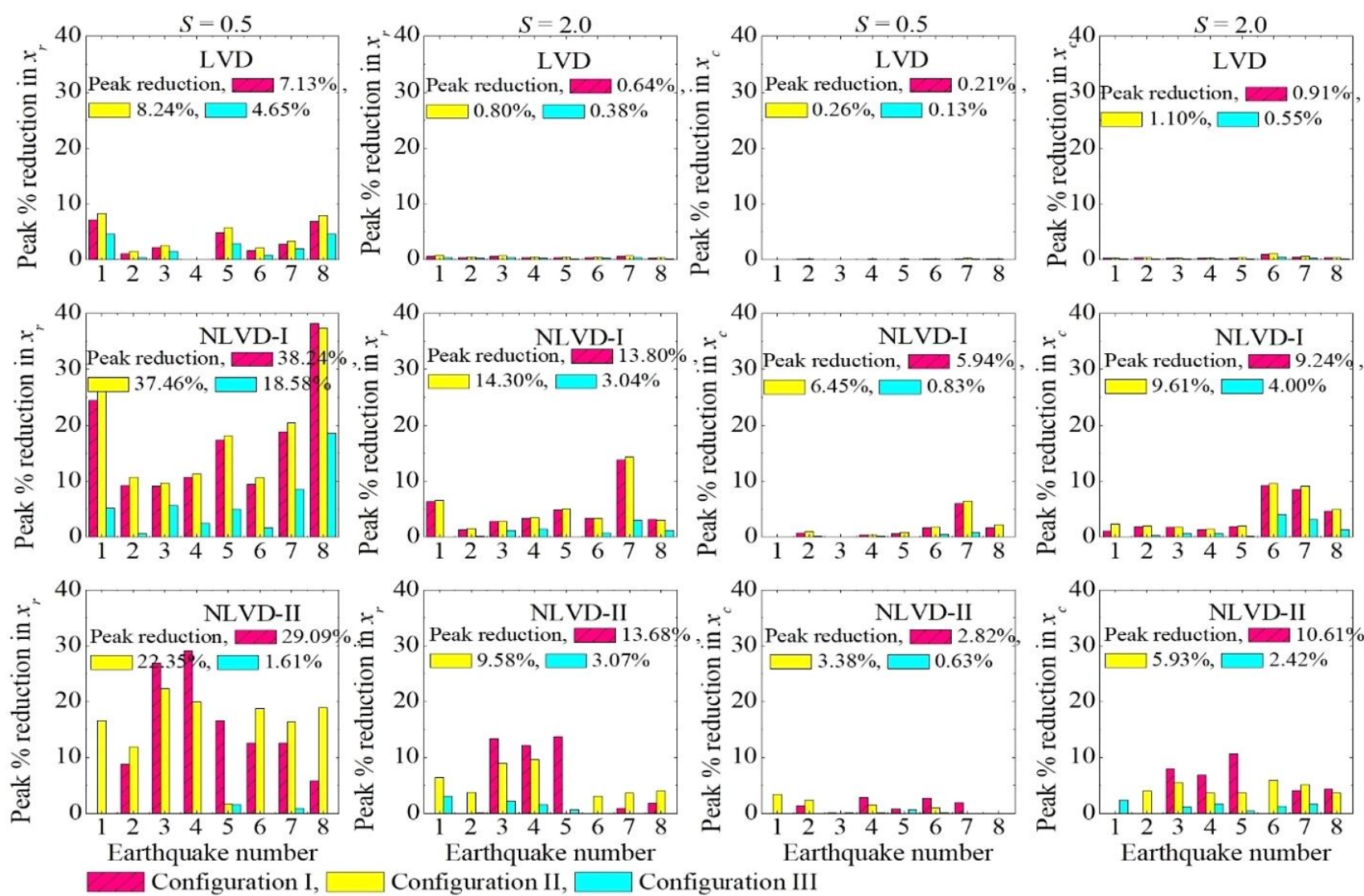

Configuration II,
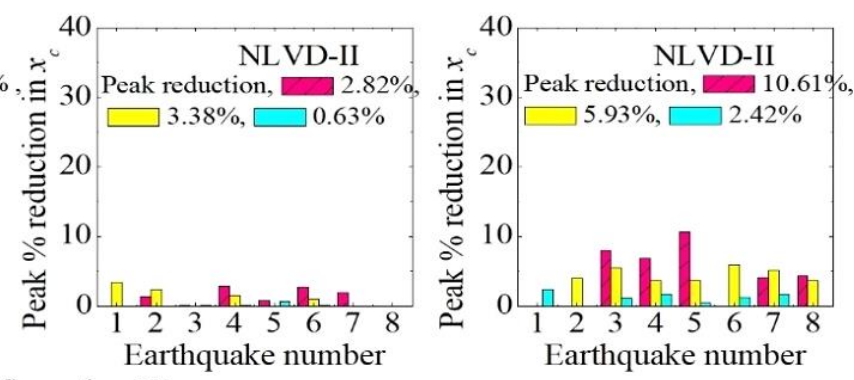

Figure 9. \% Reduction in peak seismic response quantities, rigid mass displacement $\left(x_{r}\right)$, and convective mass displacement $\left(x_{c}\right)$ for the RC elevated liquid storage tank $(S=0.5$ and $S=2.0)$ installed with the LVD $(\alpha=1)$, and NLVD-I $(\alpha=0.5)$ and NLVD-II $(\alpha=0)$, under different earthquakes.

\section{Conclusions}

The paper illustrates the importance of modeling of the elevated liquid storage tank as two-degrees of freedom system for container and as a multi-degree freedom system for the framed staging of the tank; so as to install dampers in the staging. Seismic response of the RC elevated liquid storage tank with fluid viscous dampers is investigated under eight different real earthquake ground motions. A comparison of the important response quantities, obtained through time history analysis is presented. The following are the major conclusions drawn from the present study.

- Since the dampers are installed in the staging of the elevated tank, the modeling of the multi-degree freedom system for staging provides a better tool while assessing the performance of the tank installed with dampers;

- The nonlinear viscous dampers with lower damping constant results in a comparable reduction in the response of $\mathrm{RC}$ elevated liquid storage tank to that of linear viscous dampers with higher damping constant. Lower damping constant signifies the compact size of the damper;

- The seismic response of the tank reduces with a reduction in the nonlinear exponent, $\alpha$. It is also seen that effect of damping constant increases with an increase in the PGA of earthquake ground motion;

- Typically, all fluid viscous dampers with appropriate selection of parameters, viz. damping constant and nonlinear exponent $(\alpha)$, reduce the response of elevated RC tank. Moreover, effectiveness of the fluid viscous dampers is also affected by the volume of liquid (aspect ratio, $S$ ) in the container, as such higher percentage reduction in base shear and overturning moment responses are observed for broad tank;

- The effectiveness of the dampers based on the nonlinear exponent $(\alpha)$ is anticipated due to the variation of velocities of the masses along the height of the staging;

- The effect of the nonlinear exponent on the response reduction favorably increases with an increase in the damping constant. As far as damper force is concerned, it is observed that the effect of nonlinearity in combination with damping constant makes nonlinear viscous dampers more effective than linear viscous dampers. 


\section{Conflicts of Interest}

The authors declare no conflict of interest.

\section{References}

[1] Housner, George W. "The dynamic behavior of water tanks." Bulletin of the seismological society of America 53, no. 2 (1963): 381-387.

[2] Haroun, Medhat A., and George W. Housner. "Dynamic characteristics of liquid storage tanks." Journal of the Engineering Mechanics Division 108, no. 5 (1982): 783-800.

[3] Haroun, Medhat A. "Vibration Studies and Tests of Liquid Storage Tanks." Earthquake Engineering \& Structural Dynamics 11, no. 2 (March 1983): 179-206. doi:10.1002/eqe.4290110204.

[4] Ibrahim, R. A., V. N. Pilipchuk, and T. Ikeda. "Recent Advances in Liquid Sloshing Dynamics." Applied Mechanics Reviews 54, no. 2 (March 1, 2001): 133-199. doi:10.1115/1.3097293.

[5] Ibrahim, Raouf A. "Liquid Sloshing Dynamics" (May 19, 2005). doi:10.1017/cbo9780511536656.

[6] ACI 350.3: Seismic design of liquid containing concrete structures (American Concrete Institute, Michigan (MI), USA) 2001.

[7] EN 1998-4: Euro-code 8- Design of structures for earthquake resistance -Part 4: Silos, tanks and pipelines, (European Committee for Standardization, Avenue Marnix 17 - B-1000, Brussels) 2006.

[8] Jain, S. K. and Jaiswal, O. R. "Modified proposed provisions for aseismic design of liquid storage tanks: Part I- Codal provisions." Journal of Structural Engineering, SERC, Vol. 32 No. 3 (2005) 195-206.

[9] Tung, Albert T. Y., and Anne S. Kiremidjian. "Seismic Reliability Analysis of Elevated Liquid - Storage Vessels." Journal of Structural Engineering 117, no. 5 (May 1991): 1372-1392. doi:10.1061/(asce)0733-9445(1991)117:5(1372).

[10] Malhotra, Praveen K. "New method for seismic isolation of liquid - storage tanks." Earthquake engineering \& structural dynamics 26, no. 8 (1997): 839-847. doi:10.1002/(SICI)1096-9845(199708)26:8<839::AID-EQE679>3.0.CO;2-Y.

[11] Shenton, H. W., and Hampton, F. P. "Seismic Response of Isolated Elevated Water Tanks." Journal of Structural Engineering 125, no. 9 (September 1999): 965-976. doi:10.1061/(asce)0733-9445(1999)125:9(965).

[12] Shrimali, M.K., and Jangid, R.S. "Earthquake Response of Isolated Elevated Liquid Storage Steel Tanks." Journal of Constructional Steel Research 59, no. 10 (October 2003): 1267-1288. doi:10.1016/s0143-974x(03)00066-x.

[13] Abal1, E., and Uçkan, E. "Parametric Analysis of Liquid Storage Tanks Base Isolated by Curved Surface Sliding Bearings." Soil Dynamics and Earthquake Engineering 30, no. 1-2 (January 2010): 21-31. doi:10.1016/j.soildyn.2009.08.001.

[14] Moslemi, M., Kianoush, M.R., and Pogorzelski, W. "Seismic Response of Liquid-Filled Elevated Tanks." Engineering Structures 33, no. 6 (June 2011): 2074-2084. doi:10.1016/j.engstruct.2011.02.048.

[15] Shrimali, M.K., and Jangid, R.S. "The Seismic Response of Elevated Liquid Storage Tanks Isolated by Lead-Rubber Bearing." Bulletin of the New Zealand Society for Earthquake Engineering 36, no. 3 (September 30, 2003): 141-164. doi:10.5459/bnzsee.36.3.141-164.

[16] Panchal, V. R., and Jangid, R. S. "Seismic Response of Liquid Storage Steel Tanks with Variable Frequency Pendulum Isolator.” KSCE Journal of Civil Engineering 15, no. 6 (July 2011): 1041-1055. doi:10.1007/s 12205-011-0945-y.

[17] Zhang, Ruifu, Dagen Weng, and Xiaosong Ren. "Seismic Analysis of a LNG Storage Tank Isolated by a Multiple Friction Pendulum System." Earthquake Engineering and Engineering Vibration 10, no. 2 (June 2011): 253-262. doi:10.1007/s11803011-0063-3.

[18] Chalhoub, M. S., and Kelly, J. M. “Shake Table Test of Cylindrical Water Tanks in Base - Isolated Structures.” Journal of Engineering Mechanics 116, no. 7 (July 1990): 1451 - 1472. doi:10.1061/(asce)0733-9399(1990)116:7(1451).

[19] Panchal, V. R., and Jangid, R. S. "Behaviour of Liquid Storage Tanks with VCFPS Under Near-Fault Ground Motions." Structure and Infrastructure Engineering 8, no. 1 (January 2012): 71-88. doi:10.1080/15732470903300919.

[20] Saha, S. K., Matsagar, V. A., and Jain, A. K. "Reviewing Dynamic Analysis of Base-Isolated Cylindrical Liquid Storage Tanks Under Near-Fault Earthquakes.” The IES Journal Part A: Civil \& Structural Engineering 8, no. 1 (December 23, 2014): 41-61. doi:10.1080/19373260.2014.979518.

[21] Iemura, H., Igarashi, A., Kalantari, A. "Enhancing dynamic performance of liquid storage tanks by semi-active controlled dampers." 13th World Conference on Earthquake Engineering, Vancouver, B.C., Canada, (2004).

[22] Shrimali, M. K. and Kasar, A. A. "Seismic response of connected liquid tanks with MR dampers." 15th World Conference on Earthquake Engineering, Lisbon, Portugal, (2012). 
[23] Swanson, D. B., Falkin, B., Yamatsuka, K., and Campbell, D. "Use of friction dampers on elevated water tank." 13th World Conference on Earthquake Engineering, Vancouver, B.C., Canada, (2004).

[24] Taylor, D. P. "Fluid dampers for applications of seismic energy dissipation and seismic isolation." 11th World Conference on Earthquake Engineering, Acapulco, Mexico, (1996).

[25] Goel, R. K. "Seismic Response of Linear and Non-Linear Asymmetric Systems with Non-Linear Fluid Viscous Dampers." Earthquake Engineering \& Structural Dynamics 34, no. 7 (2005): 825-846. doi:10.1002/eqe.459.

[26] Constantinou, M. C., Symans, M. D., Tsopelas, P., and Taylor, D. P. "Fluid viscous dampers in applications of seismic energy dissipation and seismic isolation" Proceedings, ATC-17-1, Seminar on Seismic Isolation, Passive Energy Dissipation and Active Control, San Francisco, California (CA), USA, (1993).

[27] Zelleke, D. H., Elias, S., Matsagar, V. A., and Jain, A. K. "Supplemental Dampers in Base-Isolated Buildings to Mitigate Large Isolator Displacement Under Earthquake Excitations." Bulletin of the New Zealand Society for Earthquake Engineering 48, no. 2 (June 30, 2015): 100-117. doi:10.5459/bnzsee.48.2.100-117.

[28] Waghmare, M. V., Madhekar, S. N., and Matsagar, V. A. "Semi-Active Fluid Viscous Dampers for Seismic Mitigation of RC Elevated Liquid Storage Tanks.” International Journal of Structural Stability and Dynamics 19, no. 03 (March 2019): 1950020. doi:10.1142/s0219455419500202.

[29] Sameer, U. S. and Jain, S. K. "Approximate methods for determination of time period of water tank stagings." The Indian Concrete Journal 66, no. 12 (1992): 691-698.

[30] Hart, G. C. and Wong, K. "Structural dynamics for structural engineers" (John Wiley and Sons, Inc., 605, Third Avenue, New York (NY), USA), (2000).

[31] MATLAB. "The Language of Technical Computing" (The Math Works Inc., 24 Prime Park Way, Natick, Massachusetts (MA), USA, 01760-1500), (2018). 